ArgOn national laboratory

ANL-08/36

\title{
Physics Design of a Cold Neutron Source for KIPT Neutron Source Facility
}

Nuclear Engineering Division 


\begin{abstract}
About Argonne National Laboratory
Argonne is a U.S. Department of Energy laboratory managed by UChicago Argonne, LLC under contract DE-AC02-06CH11357. The Laboratory's main facility is outside Chicago, at 9700 South Cass Avenue, Argonne, Illinois 60439. For information about Argonne and its pioneering science and technology programs, see www.anl.gov.
\end{abstract}

\title{
Availability of This Report
}

This report is available, at no cost, at http://www.osti.gov/bridge. It is also available on paper to the U.S. Department of Energy and its contractors, for a processing fee, from:

U.S. Department of Energy

Office of Scientific and Technical Information

P.O. Box 62

Oak Ridge, TN 37831-0062

phone (865) 576-8401

fax (865) 576-5728

reports@adonis.osti.gov

\begin{abstract}
Disclaimer
This report was prepared as an account of work sponsored by an agency of the United States Government. Neither the United States Government nor any agency thereof, nor UChicago Argonne, LLC, nor any of their employees or officers, makes any warranty, express or implied, or assumes any legal liability or responsibility for the accuracy, completeness, or usefulness of any information, apparatus, product, or process disclosed, or represents that its use would not infringe privately owned rights. Reference herein to any specific commercial product, process, or service by trade name, trademark, manufacturer, or otherwise, does not necessarily constitute or imply its endorsement, recommendation, or favoring by the United States Government or any agency thereof. The views and opinions of document authors expressed herein do not necessarily state or reflect those of the United States Government or any agency thereof, Argonne National Laboratory, or UChicago Argonne, LLC.
\end{abstract}




\title{
Physics Design of a Cold Neutron Source for KIPT Neutron Source Facility
}

\author{
by \\ Z. Zhong, Y. Gohar, and R. Kellogg \\ Nuclear Engineering Division, Argonne National Laboratory \\ work supported by the \\ Office of Global Nuclear Material Threat Reduction \\ U.S. Department of Energy Under Contract DE-AC02-06CH11357
}

November 2008 



\title{
Physics Design of a Cold Neutron Source for KIPT Neutron Source Facility
}

\author{
Table of Contents
}

Page

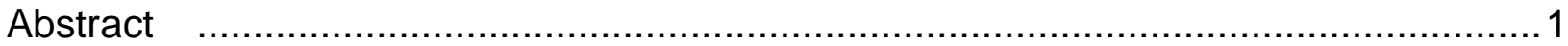

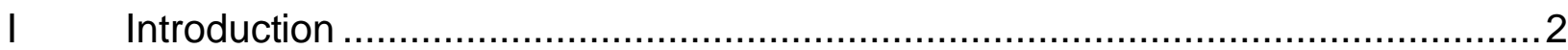

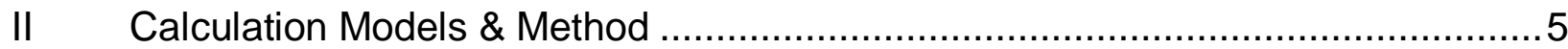

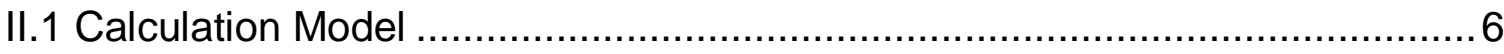

II.2 Calculation Method for Cold Neutron Source ................................................. 6

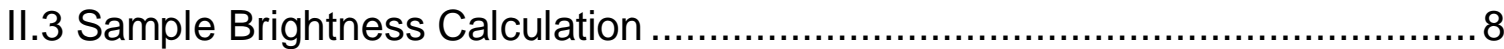

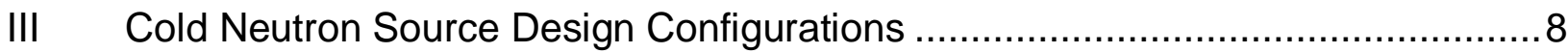

III.1 Single Cold Neutron Source Bulb with a Single Neutron Channel ................8

III.1.1 CNS Graphite Column Thickness ............................................

III.1.2 Lead shield Thickness in Front of the Cold Neutron Source ..........12

III.1.3 Cold Moderator Thickness .........................................................14

III.1.4 Cold Neutron Source Bulb Geometry.....................................16

III.1.5 Cold Moderator Gain.................................................................. 17

III.2 Single Cold Neutron Source Bulb with Multiple Neutron Channels .............. 18

III.2.1 Cold Moderator Thickness for the Single Cold Neutron Source Bulb and Multiple Neutron Channels........................................ 18

III.3 Multiple Cold Neutron Source Bulbs with Multiple Neutron Channels.........20

III.3.1 Two Cold Neutron Source Bulbs with Two Neutron Channels .......21

III.3.2 Three Cold Neutron Source Bulbs with Three Neutron Channels..23

III.3.3 Neutron Brightness Changes Due to the Use of Multiple Cold Neutron Channels .................................................................26

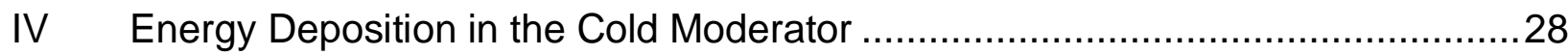

V Summary

Reference 


\section{Physics Design of a Cold Neutron Source for KIPT Neutron Source Facility}

\section{List of Figures}

Figure No.

$\underline{\text { Page }}$

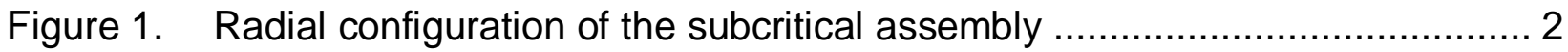

Figure 2. Neutron source configuration with a single moderator bulb and a single cold neutron source channel ........................................................... 3

Figure 3. Neutron source configuration with a single moderator bulb and three cold neutron source channels............................................................... 4

Figure 4. Neutron source configuration with two moderator bulbs and two cold neutron source channels.

Figure 5. Neutron source configuration with three moderator bulbs and three cold

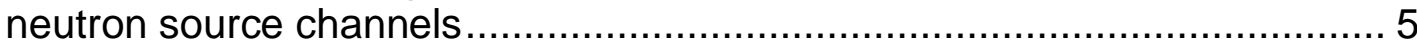

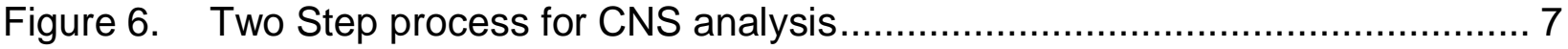

Figure 7. Cold neutron brightness as a function of the graphite column thickness..... 10

Figure 8. Cold neutron brightness as a function of the graphite column thickness..... 10

Figure 9. Cold neutron brightness as a function of the graphite column thickness..... 11

Figure 10. Neutron fluxes at the inner surface of the cold moderator pulp for para-

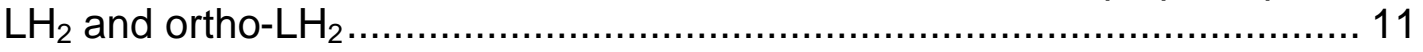

Figure 11. Neutron fluxes at the end of cold neutron channel for para- $\mathrm{LH}_{2}$ and ortho-

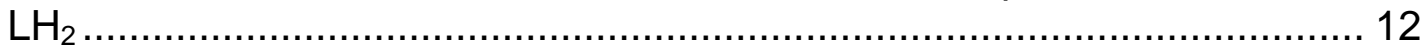

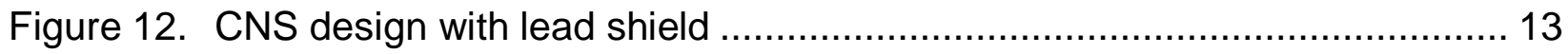

Figure 13. Gamma flux at the end of the cold neutron channel as a function .............. 13

Figure 14. Cold neutron brightness as a function of the lead shield thickness............. 14

Figure 15. Cold neutron brightness as a function of the cold moderator thickness of $100 \%$ ortho- $-\mathrm{LH}_{2}$ using single cold neutron source bulb and single neutron

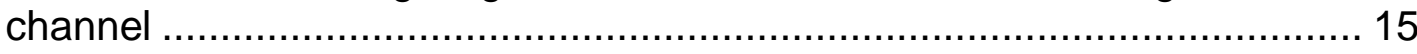

Figure 16. Cold neutron brightness as a function of the cold moderator thickness of $100 \%$ para- $\mathrm{LH}_{2}$ using single cold neutron source bulb and single neutron channel 
Figure 17. Cold neutron brightness as a function of the cold moderator thickness of $100 \%$ solid methane using single cold neutron source bulb and single neutron channel

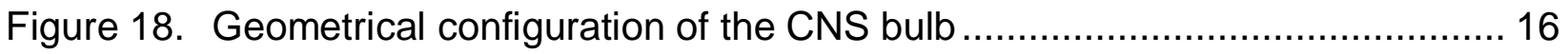

Figure 19. Cold neutron brightness as a function of the extension length of the cold moderator bulb.

Figure 20. Cold neutron brightness from $100 \%$ ortho- $\mathrm{LH}_{2}$ as a function of the cold moderator thickness of single cold neutron source bulb with multiple neutron channels

Figure 21. Cold neutron brightness from $100 \%$ para- $\mathrm{LH}_{2}$ as a function of the cold moderator thickness of single cold neutron source bulb with multiple neutron channels

Figure 22. Cold neutron brightness from $100 \%$ methane as a function of the cold moderator thickness of single cold neutron source bulb with multiple neutron channels

Figure 23. Geometrical configuration of two cold neutron source bulbs.....

Figure 24. Cold neutron brightness from $100 \%$ ortho- $\mathrm{LH}_{2}$ as a function of the cold moderator thickness for design with two cold neutron source bulbs

Figure 25. Cold neutron brightness from $100 \%$ para- $\mathrm{LH}_{2}$ as a function of the cold moderator thickness for design with two cold neutron source bulbs

Figure 26. Cold neutron brightness from $100 \%$ solid methane as a function of the cold moderator thickness for design with two cold neutron source bulbs.... 23

Figure 27. Geometrical configuration of three cold neutron source bulbs ................... 23

Figure 28. Cold neutron brightness from $100 \%$ ortho- $\mathrm{LH}_{2}$ as a function of the cold moderator thickness for design with three cold neutron source bulbs......... 24

Figure 29. Neutron brightness from $100 \%$ para- $\mathrm{LH}_{2}$ as a function of the cold moderator thickness for design with three cold neutron source bulbs........ 24

Figure 30. Neutron brightness from $100 \%$ sold methane as a function of the cold moderator thickness for design with three cold neutron source bulbs......... 25

Figure 31. Geometrical configuration of three cold neutron source bulbs .................. 25

Figure 32. Calculational models for studying multiple cold neutron channels ............. 27 


\section{Physics Design of a Cold Neutron Source for KIPT Neutron Source Facility}

\section{List of Tables}

Table No.

Table I. Energy deposition in the CNS bulbs for different lead shield thickness....... 14

Table II. Gain of the neutron brightness from different cold moderators .................. 18

Table III Cold neutron brightness for two different radial graphite length .................. 26

Table IV. Cold neutron source brightness for multiple cold neutron channels ............ 27

Table V. Nuclear energy deposition in the cold neutron source configuration with single moderator bulb and single neutron channel................................. 28

Table VI. Nuclear energy deposition in the cold neutron source configuration with two moderator bulbs and two neutron channels...................................... 29

Table VII. Nuclear energy deposition in the cold neutron source configuration with three moderator bulbs and three neutron channels ............................... 29

Table VIII. Comparison of the cold neutron source parameters for $100 \mathrm{KW}$ electron beam with 100 and $200 \mathrm{MeV}$ electron energy for cold neutron source configuration 


\title{
Physics Design of a Cold Neutron Source for KIPT Neutron Source Facility
}

\begin{abstract}
Argonne National Laboratory (ANL) of USA and Kharkov Institute of Physics and Technology (KIPT) of Ukraine have been collaborating on the conceptual design development of a neutron source facility. It is based on the use of an electron accelerator driven subcritical (ADS) facility with low enriched uranium fuel, using the existing electron accelerators at KIPT of Ukraine [1]. The neutron source of the subcritical assembly is generated from the interaction of 100-KW electron beam, which has a uniform spatial distribution and the electron energy in the range of 100 to $200 \mathrm{MeV}$, with a natural uranium target [2]. The main functions of the facility are the production of medical isotopes and the support of the Ukraine nuclear power industry. Neutron beam experiments and material studies are also included.

Over the past two-three decades, structures with characteristic lengths of $100 \AA$ and correspondingly smaller vibrational energies have become increasingly important for both science and technology [3]. The characteristic dimensions of the microstructures can be well matched by neutrons with longer vibrational wavelength and lower energy. In the accelerator-driven subcritical facility, most of the neutrons are generated from fission reactions with energy in the MeV range. They are slowed down to the meV energy range through scattering reactions in the moderator and reflector materials. However, the fraction of neutrons with energies less than $5 \mathrm{meV}$ in a normal moderator spectrum is very low because of up-scattering caused by the thermal motion of moderator or reflector molecules. In order to obtain neutrons with energy less than 5 meV, cryogenically cooled moderators "cold neutron sources" should be used to slow down the neutrons. These cold moderators shift the neutron energy spectrum down because the thermal motion of moderator molecules as well as the up-scattering is very small, which provides large gains in intensity of low energy neutrons, $\mathrm{E}<5 \mathrm{meV}$. The accelerator driven subcritical facility is designed with a provision to add a cryogenically cooled moderator system. This cold neutron source could provide the neutrons beams with lower energy, which could be utilized in scattering experiment and material structures analysis.

This study describes the performed physics analyses to define and characterize the cold neutron source of the KIPT neutron source facility. The cold neutron source is designed to optimize the cold neutron brightness to the experimental instruments outside the radial heavy concrete shield of the facility. Liquid hydrogen or solid methane with $20 \mathrm{~K}$ temperature is used as a cold moderator. Monte Carlo computer code MCNPX [4], with ENDF/B-VI nuclear data libraries, is utilized to calculate the cold neutron source performance and estimate the nuclear heat load to the cold moderator. The surface source generation capability of MCNPX code has been used to provide the possibility of analyzing different design configurations and perform design optimization analyses with reasonable computer resources. Several design configurations were analyzed and their performance were characterized and optimized.
\end{abstract}




\section{Physics Design of a Cold Neutron Source for KIPT Neutron Source Facility}

\section{Introduction}

Accelerator driven systems (ADS) are under consideration around the world in the different fuel cycle scenarios for transmuting actinides and long-lived fission products. Therefore, several studies and experiments have been performed using accelerator driven subcritical systems. As a part of the collaboration activity between the United States of America and Ukraine, Argonne National Laboratory (ANL) and the National Science Center-Kharkov Institute of Physics and Technology (NSC-KIPT) have been collaborating on developing a neutron source facility based on the use of electron accelerator driven subcritical system. The main functions of this facility are the medical isotope production and the support of the Ukraine nuclear industry. Physics experiments and material research will also be carried out utilizing the sub-critical assembly. KIPT did have a plan to construct this facility using high-enriched uranium (HEU) fuel. The collaborative studies showed that the use of low enriched uranium (LEU) instead of HEU enhances the facility performance and LEU fuel has been selected for the facility. The main system choices and design parameters of the facility are given in reference 2.

The developmental analyses defined the geometry of the subcritical assembly, the target assembly design, and its location for maximizing the neutron source strength, the fuel loading, the reflector material and thickness, and the facility performance parameters [2]. The fuel design is WWR-M2 type, which is used for Kiev research reactor [5] and other test reactors with water coolant. It has a hexagonal geometry with $3.5 \mathrm{~cm}$ pitch. The fuel material is uranium oxide in an aluminum matrix and aluminum clad with $50 \mathrm{~cm}$ active height. The U-235 enrichment is $<20 \%$. The subcritical assembly has 35 to 36 fuel assemblies surrounded by graphite reflector inside a water tank. The electron interactions with the target material produce high energy photons, which generate neutrons through photonuclear reactions with the target material. Such interactions occur at the center of the subcritical assembly and the produced neutrons drive the subcritical assembly. The radial configuration of the subcritical assembly is shown in Figure 1, which includes the target, the fuel assemblies, and the reflector assemblies.

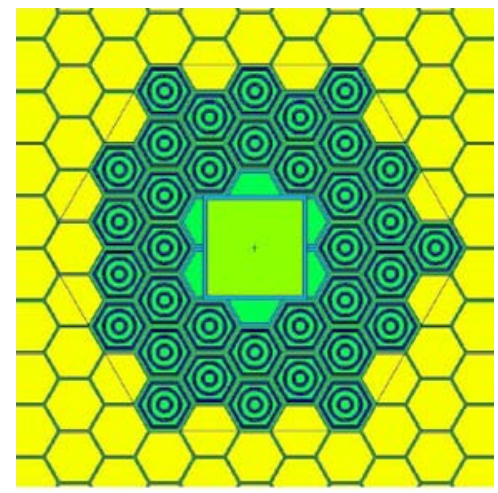

35 fuel assemblies

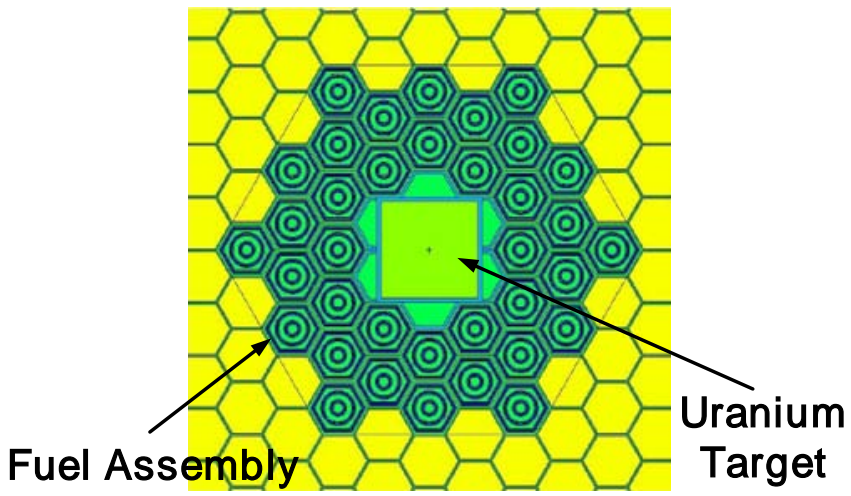

36 fuel assemblies

Figure 1. Radial configuration of the subcritical assembly 
A heavy concrete radial shield is used to attenuate the high energy neutrons generated inside the target from photonuclear reactions. The shield thickness is $180 \mathrm{~cm}$. The total thermal power of the facility is $-360 \mathrm{KW}$ for the $100-\mathrm{KW}$ electron beams and the electron energy in the range of 100 to $200 \mathrm{MeV}$. The maximum flux inside the subcritical assembly is $>10^{13} \mathrm{n} / \mathrm{s} \cdot \mathrm{cm}^{2}$.

To generate a cold neutron source (CNS) with a high intensity, special moderator (e.g. liquid hydrogen or solid methane) is utilized to slow down the neutrons from thermal range $(10 \sim 100 \mathrm{meV})$ to meV energy range. To maximize the CNS intensity, the CNS moderator is installed inside the water tank, close to the graphite reflector boundary to obtain the maximum possible thermal neutron current. The configuration and the arrangement of the CNSs are shown in Figure 2 through 5 . These configurations were explicitly modeled for Monte Carlo analyses, with different number of CNS bulbs and neutron channels. In the neutron source facility, there are several radial neutron channels inside the radial shield. These channels have insignificant impact on the CNS source performance, therefore these channels are neglected in the cold neutron analyses. Open spherical shell geometry is utilized for the cold neutron source moderator and the thickness of moderator (liquid hydrogen or solid methane) shell is about $3.0 \sim 4.0 \mathrm{~cm}$. The outer radius of the sphere is $\sim 6.0 \mathrm{~cm}$ for the configuration shown in Figure 2, 4, and 5 , and it is $\sim 12.0 \mathrm{~cm}$ for the configuration shown in Figure 3. Extra graphite is used around the cold neutron channel, since it increases the neutron flux level in the CNS channel. Different configurations of moderator bulbs and cold neutron channels are considered. In Figures 2 and 3 , a single

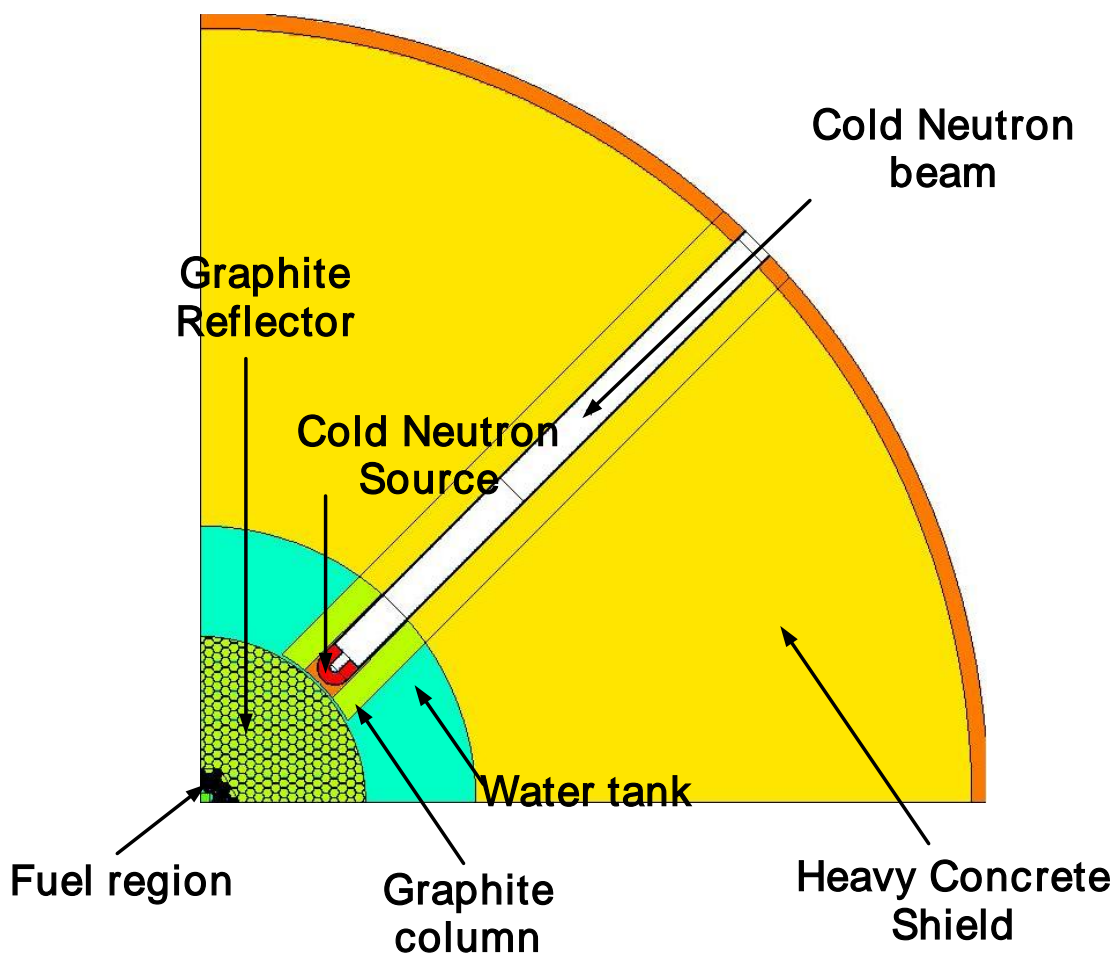

Figure 2. Neutron source configuration with a single moderator bulb and a single cold neutron source channel 


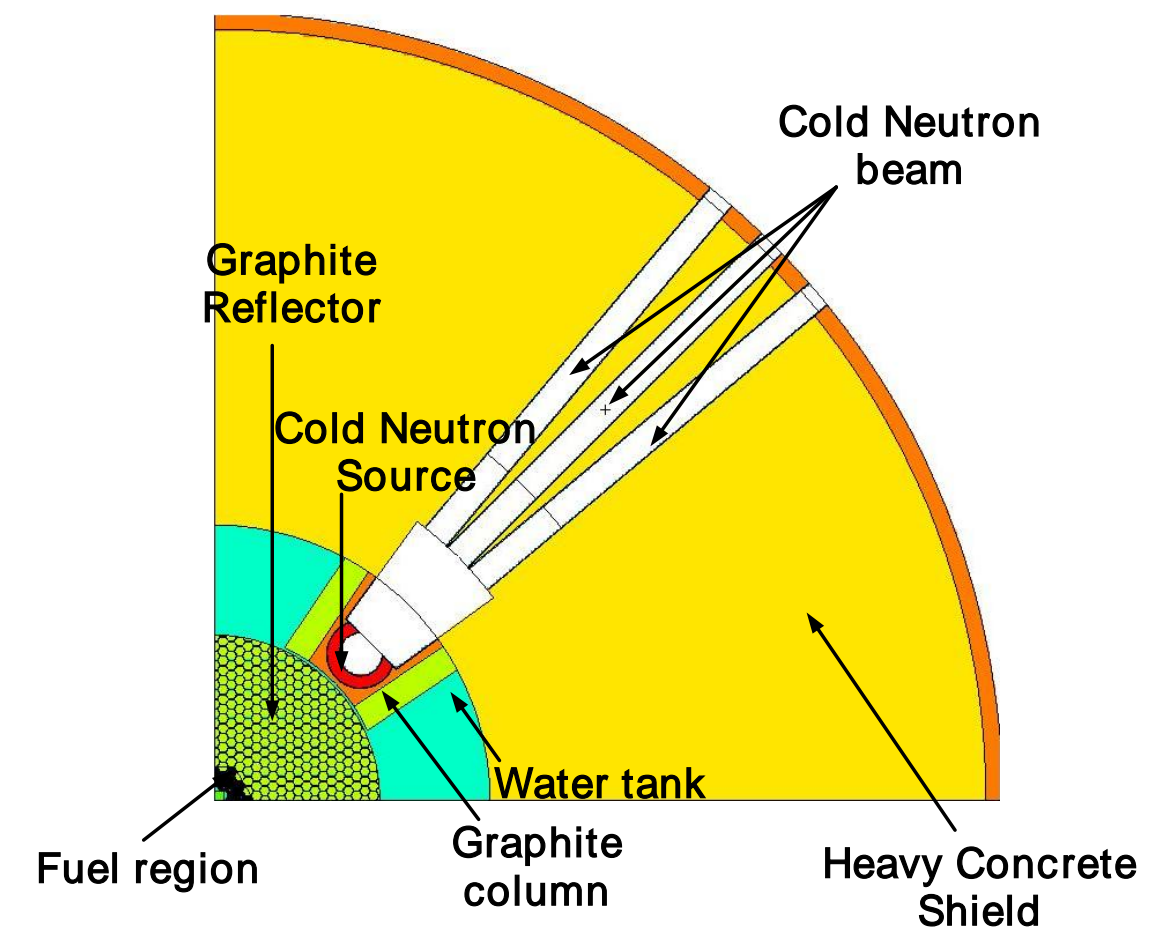

Figure 3. Neutron source configuration with a single moderator bulb and three cold neutron source channels

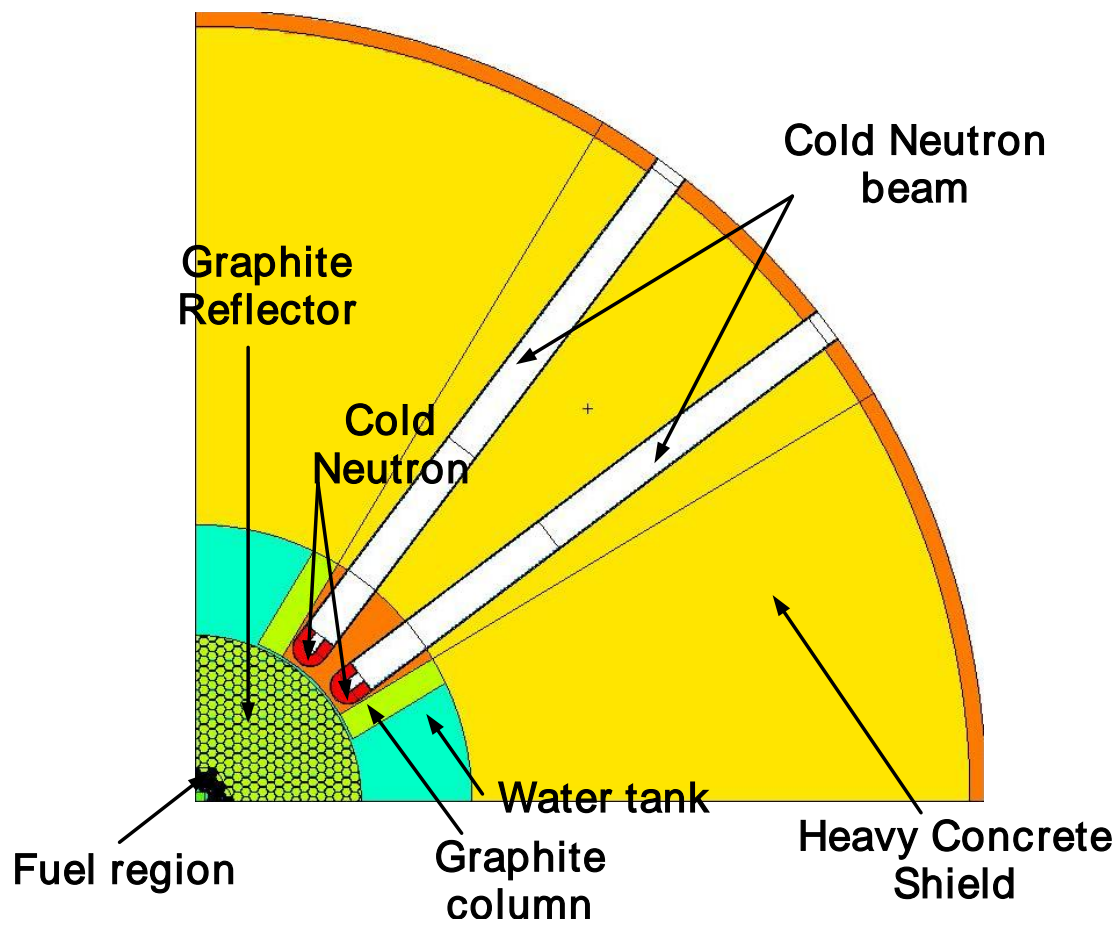

Figure 4. Neutron source configuration with two moderator bulbs and two cold neutron source channels 


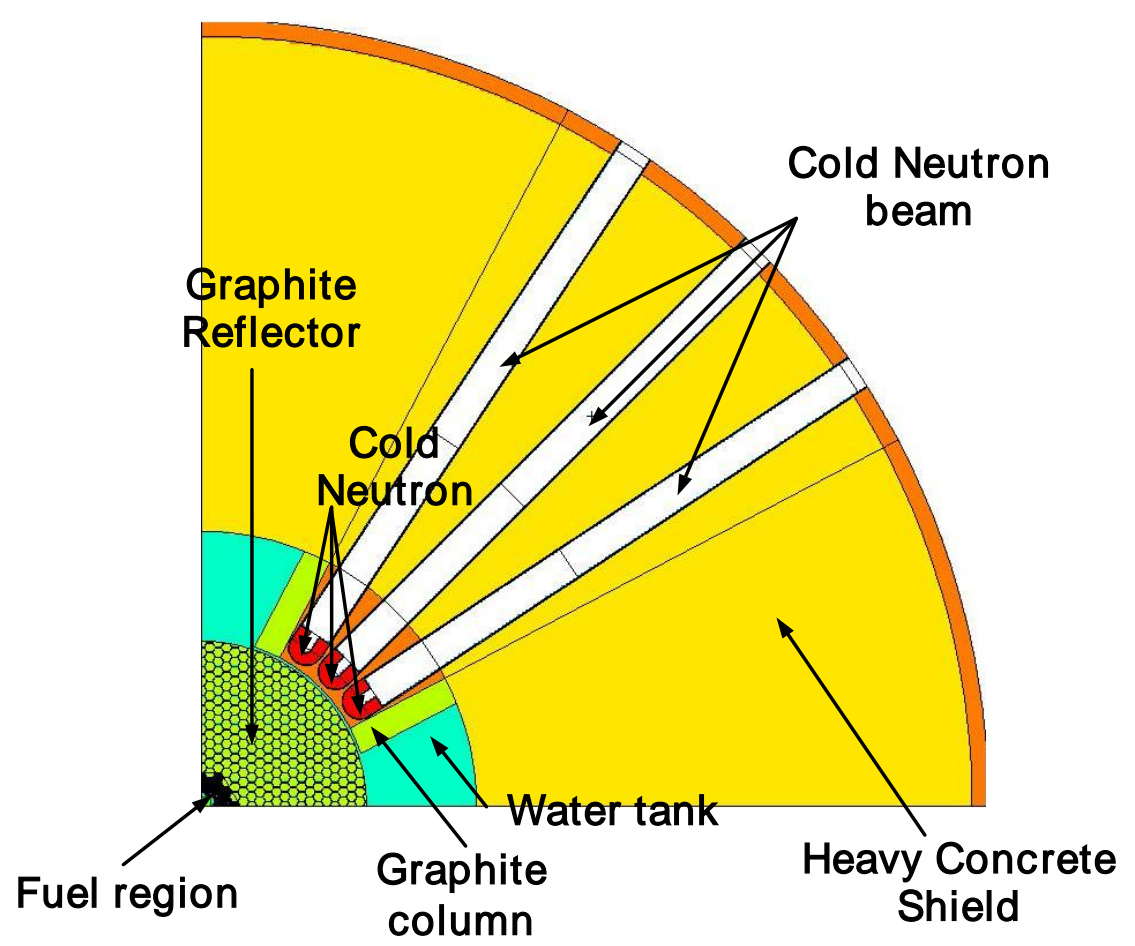

Figure 5. Neutron source configuration with three moderator bulbs and three cold neutron source channels

moderator bulb is used for one and three cold neutron source channels. Configurations with multiple moderator bulbs are shown in Figures 4 and 5 where each cold neutron channel has its moderator bulb. The radius of the neutron channel is in the range of 5.0 to $6.0 \mathrm{~cm}$.

\section{Calculation Models \& Method}

The physics analyses of cold neutron source need accurate characterization of the neutrons flux through the cold moderator and the neutron channel. This requires electrons, neutrons, and photons transport through the main components including the target, the fuel, the reflector, and the cold moderator. The electron interactions with the target material produce high-energy photons, which generate neutrons through photonuclear reactions with the target material. Such process occurs at the center of the assembly and the produced neutrons reaching the nuclear fuel for driving the subcritical assembly. The neutron leakage from the graphite reflector is used for producing cold neutrons. The cold neutrons represent a very small fraction of the total neutron population, which represents a computational challenge to obtain an accurate prediction. A calculational procedure was developed to overcome this difficulty based on two calculational steps without any approximations or sacrificing any geometrical details and it results in an accurate prediction. 


\section{II.1 Calculation Model}

A three dimensional model has been developed for transporting electrons, neutrons, and photons using the Monte Carlo transport computer code, MCNPX [4]. In the MCNPX calculation model, the target, fuel, reflector sections are presented explicitly without any geometrical approximation or material homogenization. Electron source calculation is performed simulating the interaction of electrons with target for generating photons and neutrons. Due to the fact that the electron transport is very slow, the electrons with energy below $1.0 \mathrm{MeV}$ are terminated in the calculation to save computer time since they do not contribute to the neutron source generation from the target.

The configuration with 36 fuel assemblies is used for the cold neutron source analyses. Because of the symmetry of the target, fuel assemblies and reflector blocks, a three dimensional quarter model is used in the calculations, which saves computer times. The three-dimensional quarter model of MCNPX is shown in Figure 2 through 5 for different cold neutron source configurations. In the quarter model, it is assumed that the cold neutron sources and associated parts are symmetric. This assumption has insignificant effect on the results since the cold neutron source channel is away from the model boundaries.

In addition to the explicit modeling of the geometrical details, MCNPX has the advantage of being able to use pointwise cross-section data libraries for the transport calculations [4]. The data libraries of MCNPX have cross section files four cold moderators including ortho- $\mathrm{LH}_{2}$ and para- $\mathrm{LH}_{2}$ in $1 \mathrm{~K}$ intervals from $19 \mathrm{~K}$ to $25 \mathrm{~K}$, and hydrogen in solid methane at $22 \mathrm{~K}$ temperature.

\section{II.2 Calculation Method for Cold Neutron Source}

The figure of merit for judging the performance of a cold neutron source is the "brightness" in the direction of the beams or guides to various instruments. Brightness, defined as $d^{2} \Phi / d \lambda d \Omega$, has the units of neutrons $/ \mathrm{cm}^{2}$-s- $\AA$-ster in terms of neutron wavelength, or $d^{2} \Phi / d E d \Omega$ with units of neutrons $/ \mathrm{cm}^{2}$-s-meV-ster in terms of neutron energy. Specially, it's the brightness of cold neutrons with $E<5 \mathrm{meV}$ or $\lambda>4 \AA$, in the angles less than the critical angle for reflection from the $\mathrm{Ni}^{58}$ coated surfaces within the guides [3]. The critical angle is $\theta_{c}=0.002 \lambda(\AA)$ rad for $\mathrm{Ni}^{58}[3]$.

The direct calculation of the neutron current inside the neutron source channel with detailed energy and angular distribution is challenging calculational problem for several reasons. The first reason is that the neutron yield is only about 0.1 neutrons per electron for the $200 \mathrm{MeV}$ electron and 0.05 neutrons per electron for the $100 \mathrm{MeV}$ electron beams [6]. Another reason is that only a very small fraction of neutrons generated in the target can reach the cold neutron moderator due to the long distance between the cold neutron channel and the target as well as the small cross section area of the cold neutron channel. To solve this problem, the cold neutron brightness is calculated in a two step process [3]. In the first step, a three-dimensional geometrical quarter model is used and a surface source file is being generated, using the SSW card 
of MCNPX, for neutrons and photons entering the cold source region. In the second step, the surface source file generated from the first step is used in another calculation. A much smaller model is used in the second calculation and it requires much less computational resources. In the second step, the particles recorded on the source file are used several times to reduce the statistical error of the calculated tally [4]. This two step procedure can accurately calculate the cold neutron source brightness by MCNPX.

The surface source file surrounds the boundary of the cold neutron source and it contains the location, direction, energy, and weight of each recorded neutron and photon for the second MCNPX calculation. The surface source file was generated from electrons, photons and neutrons transport calculation using the whole geometrical model (one quarter of the configuration) including the cold neutron source. In the first step, MCNPX transported 120 million electrons to get an accurate surface source file with a small statistical uncertainty. This large number of electrons is needed because of the small neutron yield through photonuclear reactions inside the target. The source file records all the particles crossing the surface. A single neutron may pass into and out of the cold neutron source boundary several times and it is recorded each time.

In the second step, the model contains the cold neutron source including the cold neutron beam channel is used, as shown in Figure 6. The SSR card of MCNPX is used to read the source file generated from first step. All the recorded particles are sampled in the second calculation to preserve the correct normalization [4]. It is possible to sample the source file several times to reduce the tally statistical error. However, the minimum statistical error is limited by the statistical error of the source file [4]. Therefore, it is recommended to reduce the statistical error of the first MCNPX calculation for generating the surface source file.

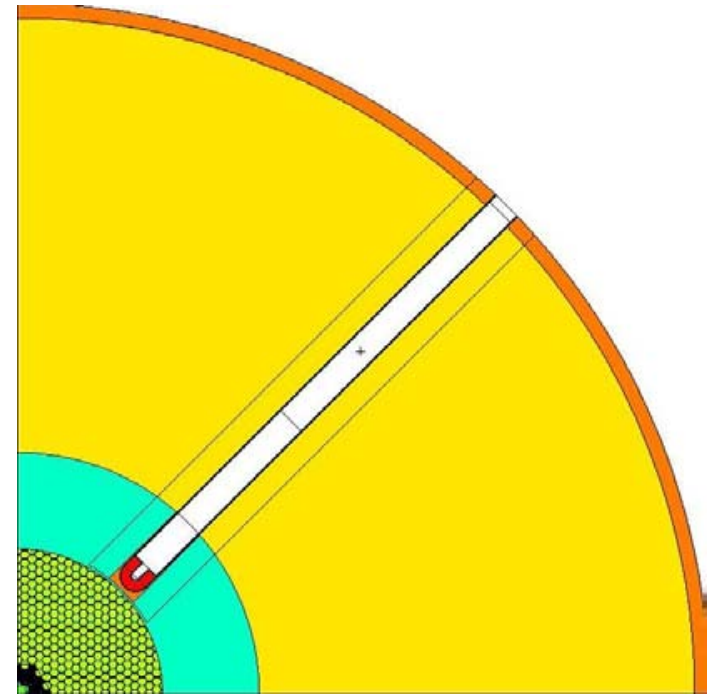

First Step calculation

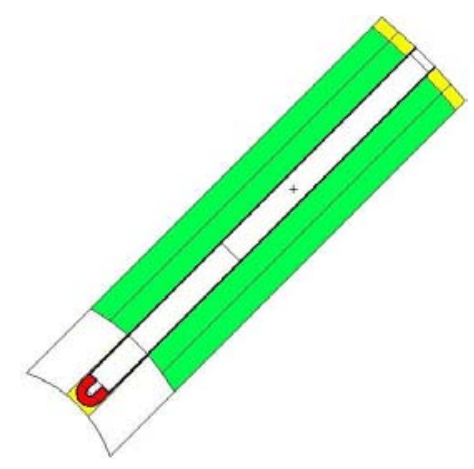

Second Step calculation

Figure 6. Two Step process for CNS analysis 
The model of the second step is shown in Figure 6, which requires a very small fraction of the used computational resources for the first step. The expensive calculation for electron transport inside target and the neutron multiplication in the fuel region is avoided in the second step. Another advantage of the two step calculations that the effects from small changes in the cold neutron geometry could be studied quickly using the same source. Therefore the second step calculation can be used to optimize the cold neutron source geometry. A large geometry change, such as changing the thickness of graphite surrounding the cold neutron source, changes considerably the recorded current on the surface source file, and a new surface source file should be generated.

In the second step calculation with MCNPX, a simple variance reduction technique is utilized, the importance of the cells increases along the interested direction, although the tracked particles cannot be split in the void region inside the neutron channel. The neutron importance increases from 1 to 27 as neutrons move from the surface source toward the $\mathrm{LH}_{2}$ cell. In this way, neutrons will be split before they enter the void channel, although they cannot split further inside the void channel. This simple variance reduction technique provides tallies with small statistical errors in relatively short computation time.

\section{II.3 Sample Brightness Calculation}

Let the brightness be $d^{2} J / d E d \Omega=B$. Its units are $n / \mathrm{cm}^{2}-s-m e V$-ster, and its value should not depend on the distance of the tally surface from the cold source, if the tally surface is on the beam axis and is fully illuminated [3].

Let $F(E, \Omega)$ be the MCNP current tally per unit area in energy bin $d E$ and cosine bin $d \mu$ times the reactor normalization at full power, $1.56037150{ }^{15}$ for the $100 \mathrm{MeV}$ electron beam with beam power $25 \mathrm{~kW}$ ( for quarter model).

Then $F(E, \Omega)=B \times d E \times d \Omega$, where $d \Omega=2 \times \pi \times d \mu$.

So $B=F(E, \Omega) /[(2 \pi) d E d(\cos \theta)]$.

For the model shown in Figure 6 , the calculated current is $F(E, \Omega)=1.80588 \times 10^{5}$ $\mathrm{n} /\left(\mathrm{s} \cdot \mathrm{cm}^{2}\right)$, for $0<\mathrm{E}<1 \mathrm{meV}$, and $0.9998<\theta<1.0000$. Then we have $\mathrm{dE}=1 \mathrm{meV}, \mathrm{d}$ $(\cos \theta)=\mathrm{d} \mu=1-0.9998=0.0002$, and $B=1.44 \times 10^{8} \mathrm{n} / \mathrm{cm} 2-\mathrm{s}-\mathrm{meV}$-ster.

\section{Cold Neutron Source Design Configurations}

Several cold neutron source configurations are analyzed to define their performance. The main objective is to define their performance to select the most appropriate design configuration based on the source brightness and the possible flexibility to accommodate different operating conditions and experiments.

\section{III.1 Single Cold Neutron Source Bulb with a Single Neutron Channel}

The geometrical model of a single CNS bulb with a single neutron channel is shown in Figure 2. A parametric study was performed to understand the CNS 
performance as a function of the graphite column thickness, the cold moderator thickness, and the geometry of the cold moderator bulb. The inner radius of the neutron channel is $\sim 6.0 \mathrm{~cm}$, and the outer radius of the cold moderator bulb is also $\sim 6.0 \mathrm{~cm}$. Liquid hydrogen and solid methane are the cold moderator materials.

Liquid hydrogen $\left(\mathrm{LH}_{2}\right)$ has two different states according to the spin directions of the two atoms of the hydrogen molecule. If the spin of the two hydrogen atoms are aligned it is a para hydrogen otherwise is ortho hydrogen. For neutrons with energy less than $30 \mathrm{meV}$, the neutron scattering cross section for ortho and para hydrogens are very different. The ortho hydrogen scattering cross section is an order of magnitude higher than that of para hydrogen [7]. Due to this fact, the performance of CNS is sensitive to the ratio of ortho and para molecules in the hydrogen moderator. The concentration of para hydrogen is $\sim 25 \%$ at room temperature, and if hydrogen is cooled from room temperature to cryogenic temperature and left undisturbed for many hours, the spin states will tend to align, and para hydrogen becomes the dominant form. In this study, due to the MCNPX modeling constraint of the two-phase system, only single phase hydrogen is used as a cold moderator, with $100 \%$ para- $\mathrm{LH}_{2}$ or $100 \%$ ortho- $\mathrm{LH}_{2}$ respectively. The case of $100 \%$ ortho- $\mathrm{LH}_{2}$ is not physically possible.

Solid methane is also utilized as cold moderator. Due to the higher atomic density of hydrogen in solid methane than liquid hydrogen, about $50 \%$ more atoms, it has a better performance than the liquid hydrogen.

\section{III.1.1 CNS Graphite Column Thickness}

Graphite column surrounds the cold neutron source as a reflector to increase the neutron flux level at the CNS, as shown in Figure 2 to 5 . The thickness of the cylindrical graphite column is varied in a series of MCNPX calculations to define the cold neutron source performance.

The brightness of the cold neutron source is shown in Figure 7 to 9 as a function of the graphite column thickness using $100 \%$ para- $\mathrm{LH}_{2}, 100 \%$ ortho- $-\mathrm{LH}_{2}$ and $100 \%$ solid methane as cold moderator, respectively. The cold moderator thickness is $2.2 \mathrm{~cm}$ for the liquid hydrogen and $1.7 \mathrm{~cm}$ for the solid methane. The results for the three cases show that the cold neutron brightness increases as the thickness of the graphite column increases. When the thickness of graphite column is $40 \mathrm{~cm}$, the cold neutron brightness is $\sim 2$ times the obtained value without graphite. The cold neutron brightness reaches a saturated value at about $50 \mathrm{~cm}$ graphite thickness. Therefore, the required thickness of graphite column thickness is $\sim 50 \mathrm{~cm}$ for all these three cases. However, the brightness increase is very small as the graphite thickness increases from 30 to $50 \mathrm{~cm}$. In addition, the design configuration limits the possible graphite thickness to less than $30 \mathrm{~cm}$ to avoid interference with other neutron channels inside the water tank.

The neutron brightness results of Figure 7 and 8 show that para- $\mathrm{LH}_{2}$ and ortho$\mathrm{LH}_{2}$ have same performance when the moderator thickness is $2.2 \mathrm{~cm}$. These results are different from the results of the National Institute of Standards and Technology 
(NIST) [3]. For $10-\mathrm{cm}$ graphite column thickness of $10 \mathrm{~cm}$, the neutron flux at the inner surface of the cold moderator sphere and at the end of cold channel are plotted for $100 \%$ para- $\mathrm{LH}_{2}$ and $100 \%$ ortho- $-\mathrm{LH}_{2}$ in Figure 10 and 11 . For ortho- $\mathrm{LH}_{2}$, the cold neutron flux at the inner moderator surface is $\sim 2$ times the value obtained with para- $\mathrm{LH}_{2}$. This result is due to the larger scattering cross section of ortho- $\mathrm{LH}_{2}$ is larger than that of para- $\mathrm{LH}_{2}$.

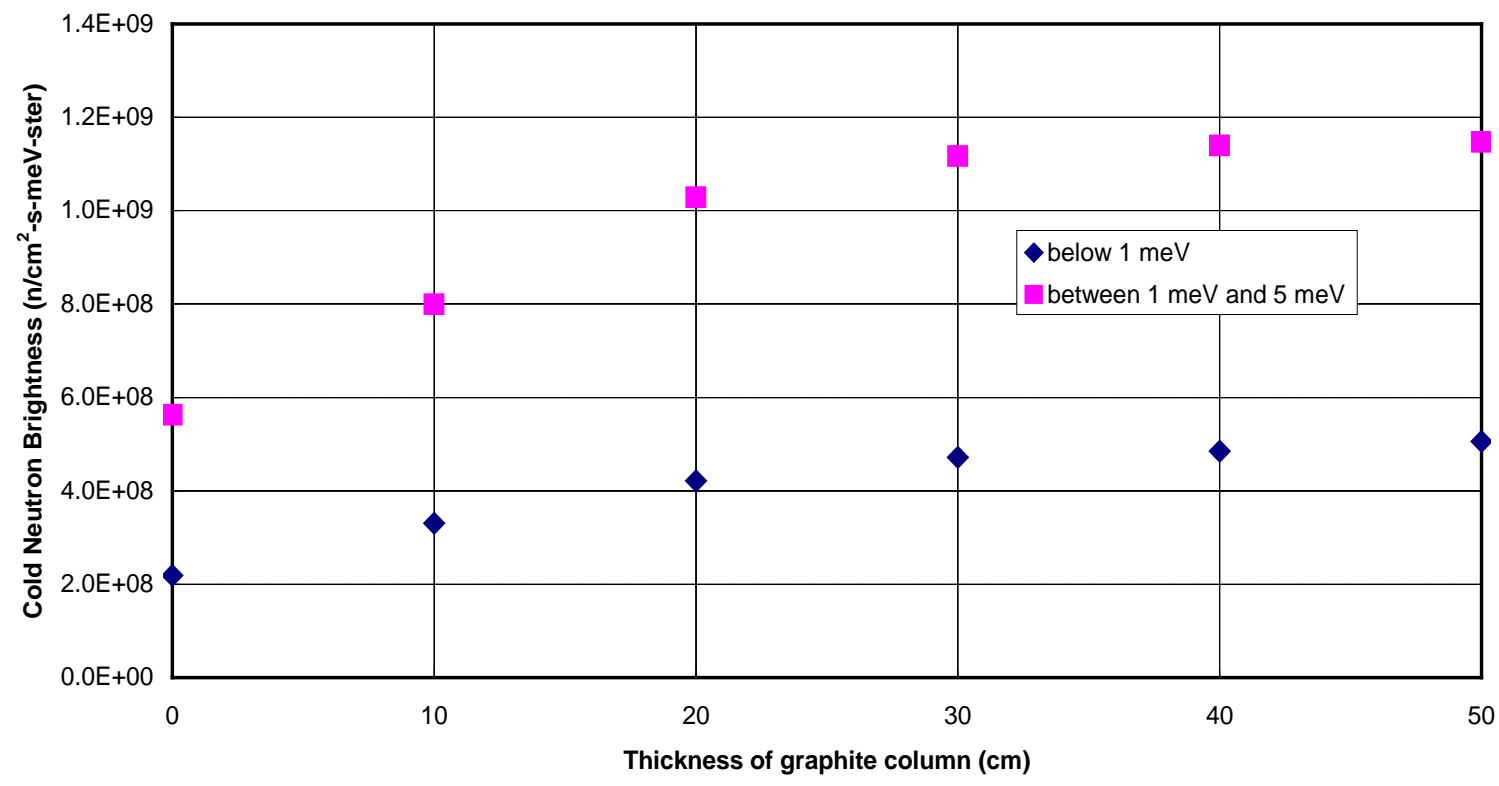

Figure 7. Cold neutron brightness as a function of the graphite column thickness with $100 \%$ para- $\mathrm{LH}_{2}$

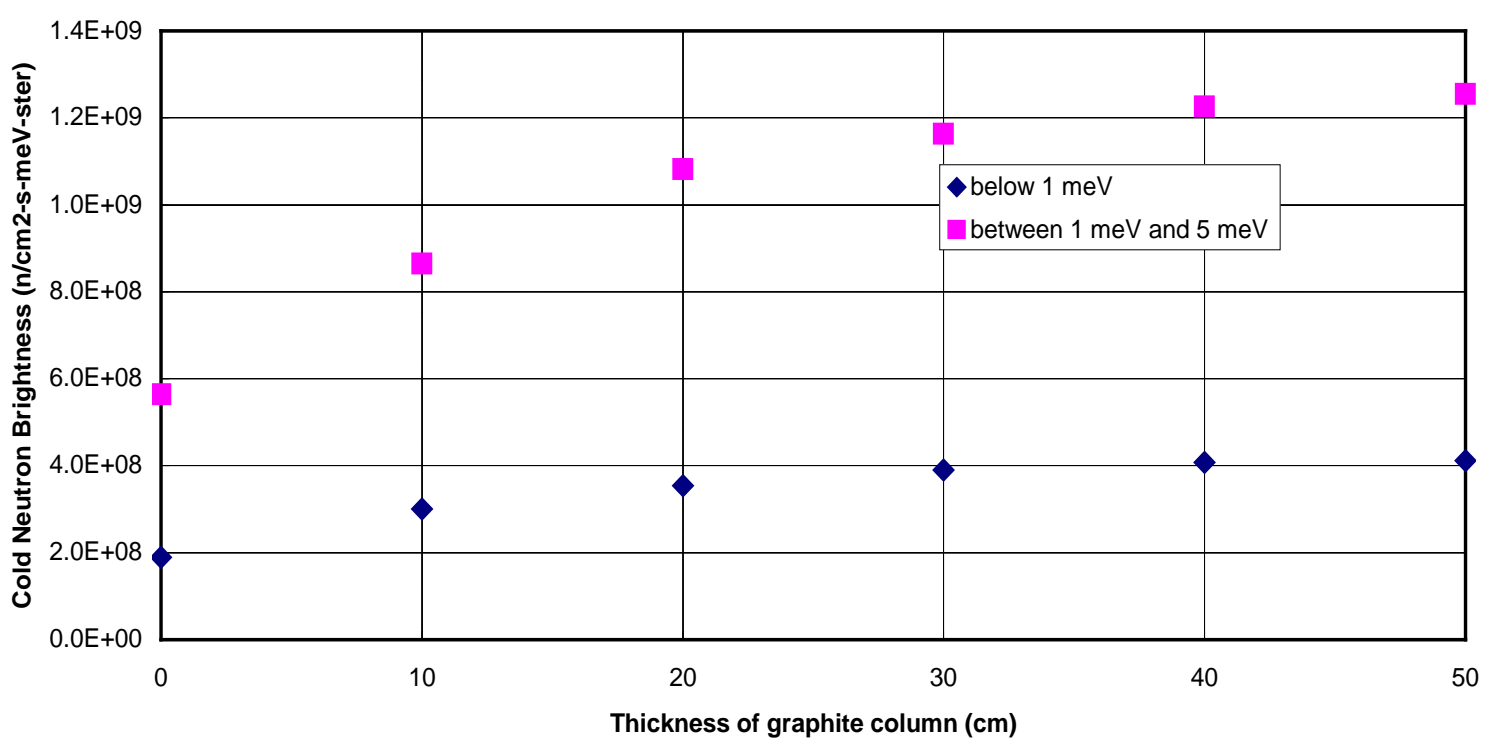

Figure 8. Cold neutron brightness as a function of the graphite column thickness with $100 \%$ ortho- $\mathrm{LH}_{2}$ 
At the end of the cold neutron channel, the cold neutron flux from the ortho- $\mathrm{LH}_{2}$ is slightly lower smaller than that from para- $\mathrm{LH}_{2}$. The difference between these results and the corresponding NIST results could be due to the geometry differences. The obtained results are similar to the results of the HFIR cold neutron source [7].

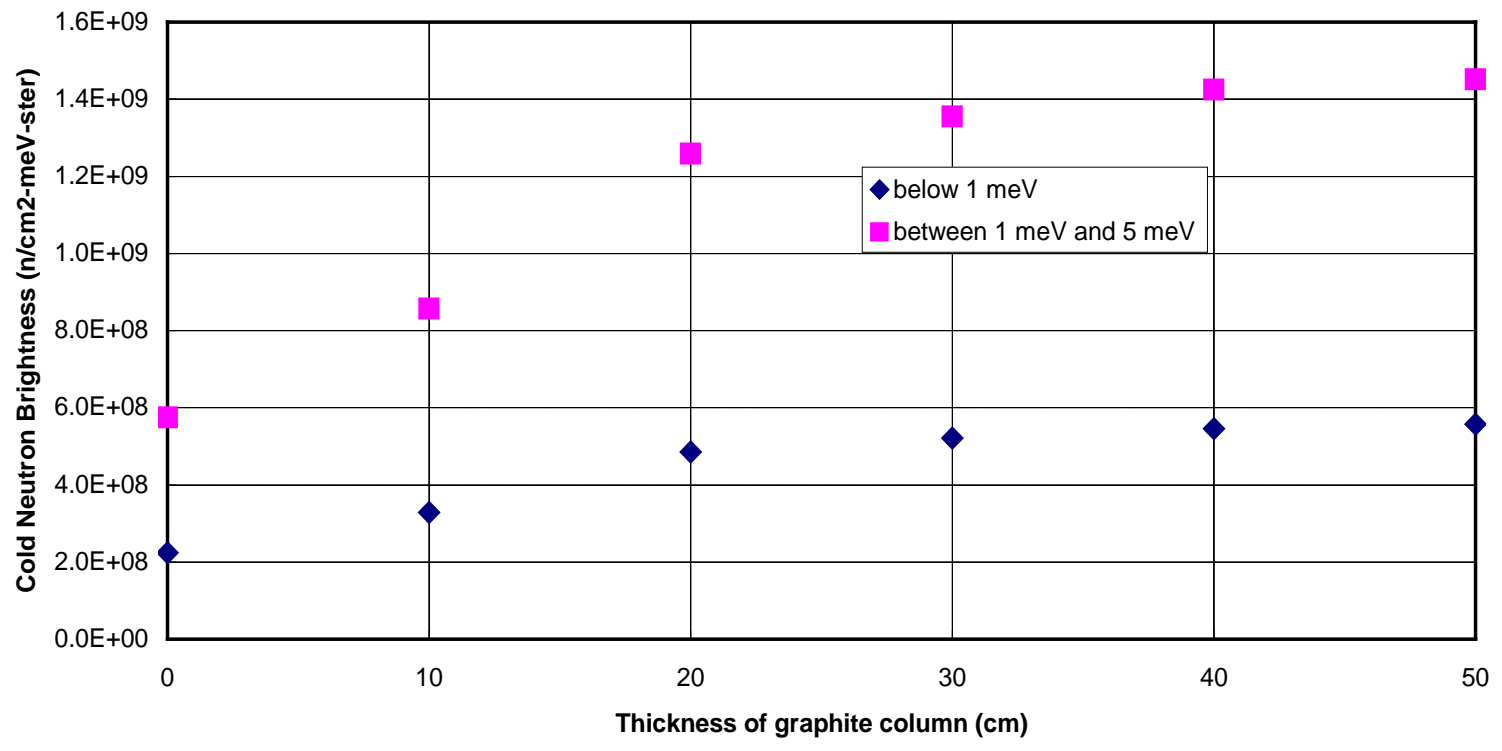

Figure 9. Cold neutron brightness as a function of the graphite column thickness with $100 \%$ solid methane

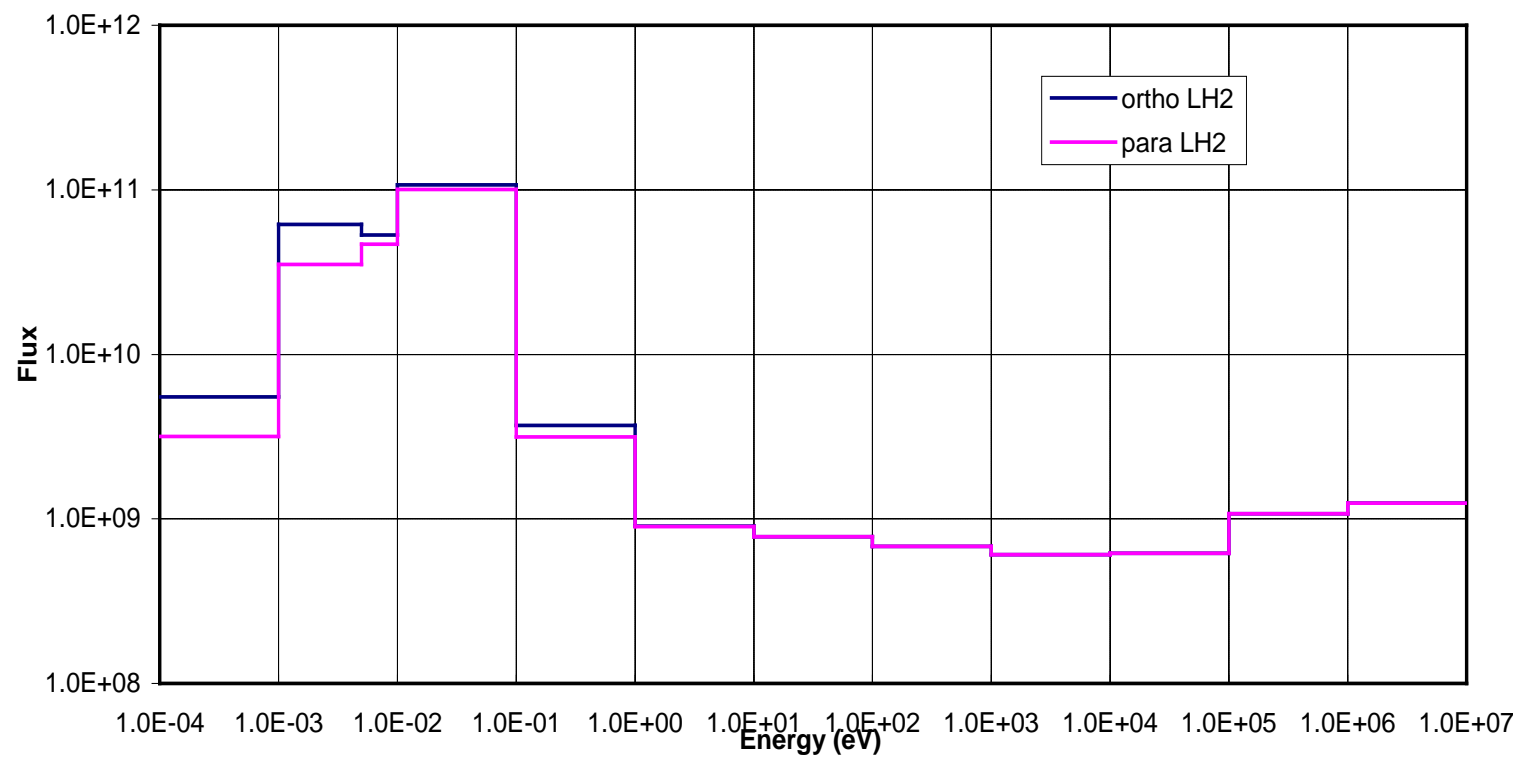

Figure 10. Neutron fluxes at the inner surface of the cold moderator pulp for para- $\mathrm{LH}_{2}$ and ortho- $\mathrm{LH}_{2}$ 


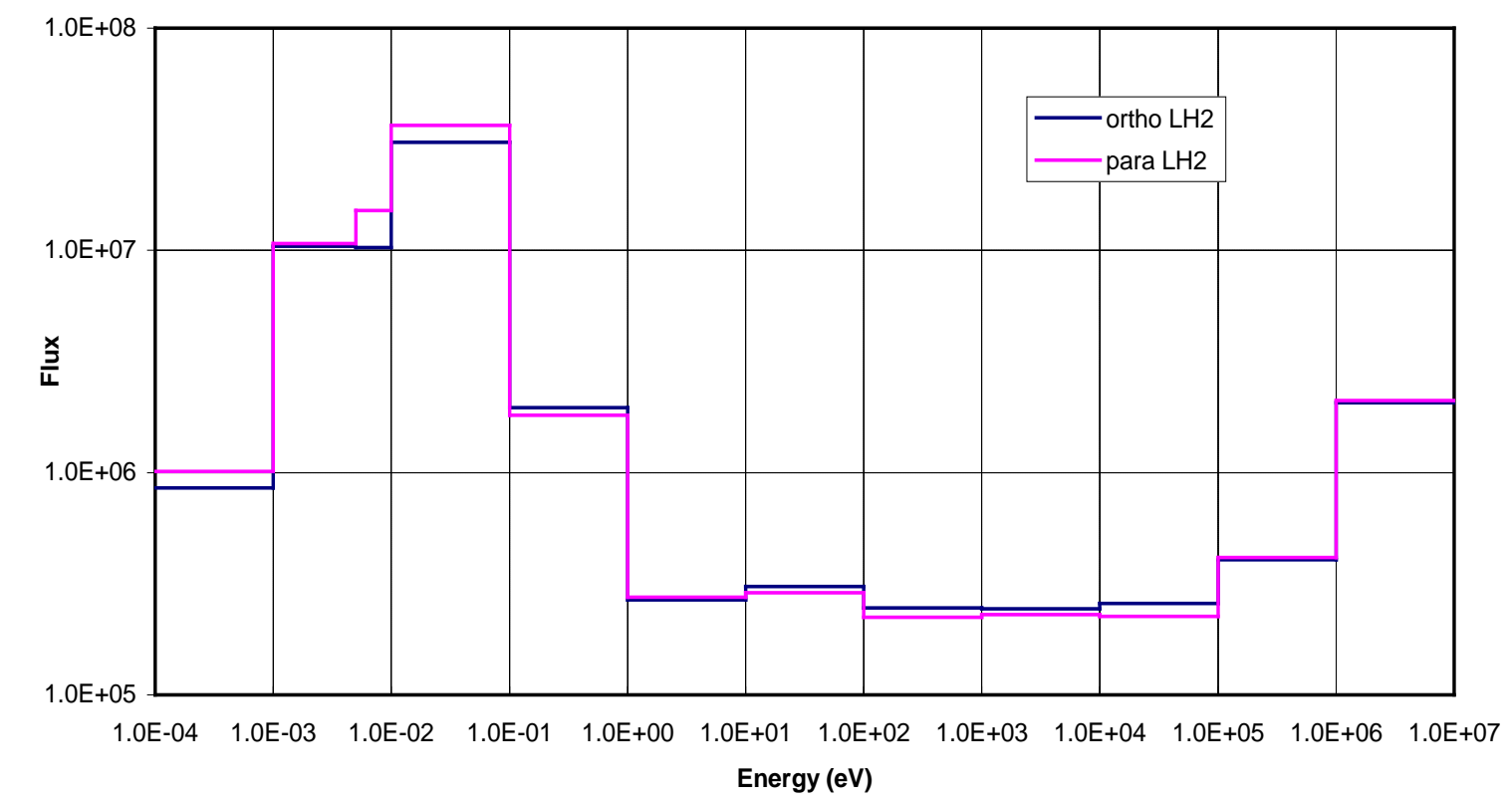

Figure 11. Neutron fluxes at the end of cold neutron channel for para- $\mathrm{LH}_{2}$ and ortho- $\mathrm{LH}_{2}$

\section{III.1.2 Lead shield Thickness in Front of the Cold Neutron Source}

Lead material is used to reduce the gamma flux at the end of the cold neutron source channel. The lead neutron absorption is negligible for neutron energy above 10 meV but it increases considerably for cold neutrons with energy less than $10 \mathrm{meV}$. If the lead is installed inside the cold neutron channel, it will also reduce the cold neutron flux considerably. Therefore, the lead is installed in front of the CNS inside the graphite reflector as shown in Figure 12. In this configuration, the cryogenic heat load is reduced since the gamma heating of the lead shield is removed by the graphite reflector coolant.

MCNPX calculations have been performed to define the lead shield thickness for reducing the gamma flux at the end of neutron channel as much as possible without impacting the CNS performance. The gamma flux at the end of cold neutron channel as a function of the lead shield thickness is shown in Figure 13. In addition, the brightness of the cold neutron source as a function of the lead shield thickness is shown Figure 14. It is observed that the cold neutron brightness is not sensitive to the lead shield thickness. The gamma flux drops exponentially as the shield thickness increases. For the first $5 \mathrm{~cm}$ of lead shield, the gamma flux at the end of channel is reduced by a factor of five and it reach a saturated value as the lead shield thickness increases. Therefore, the selected shield thickness is $5.0 \mathrm{~cm}$ to minimize the impact on the graphite reflector thickness and simplify the mechanical design. In these set of calculations, $4.2 \mathrm{~cm}$ of para- $\mathrm{LH}_{2}$ is used as cold moderator with $10.0 \mathrm{~cm}$ graphite column thickness.

The energy deposition in the cold moderator and the bulb clad is also calculated as a function of the lead shield thickness. The obtained results are given in Table I. The photon heating in the cold neutron source decreases as the lead shield thickness increases. However, the neutron heating increases because the lead neutron 
absorption is less than that of the graphite reflector. The total nuclear, neutron and photon, heating decreases as the lead shield thickness increases.

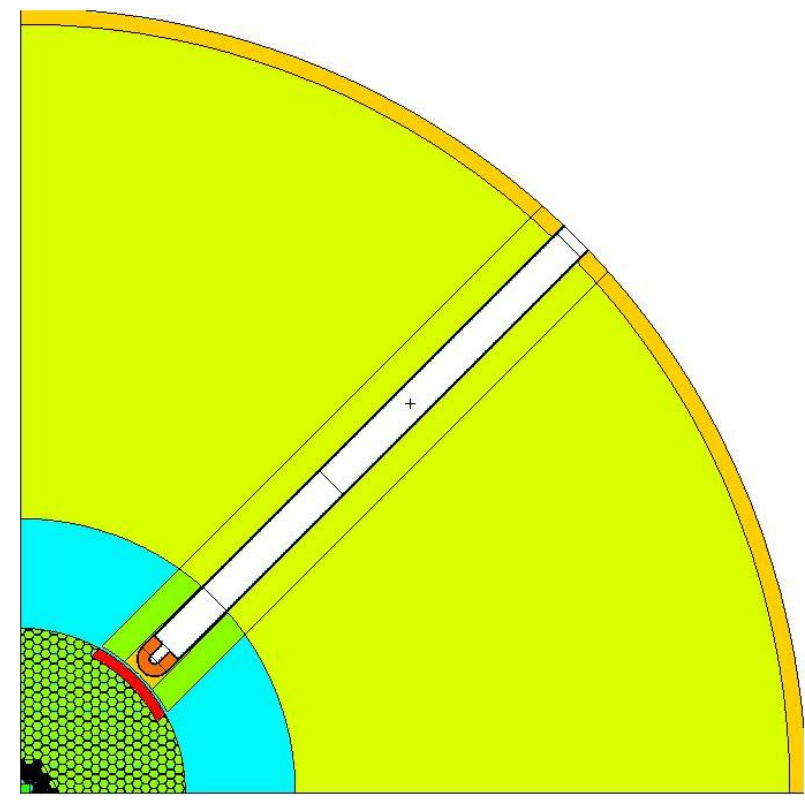

Figure 12. CNS design with lead shield

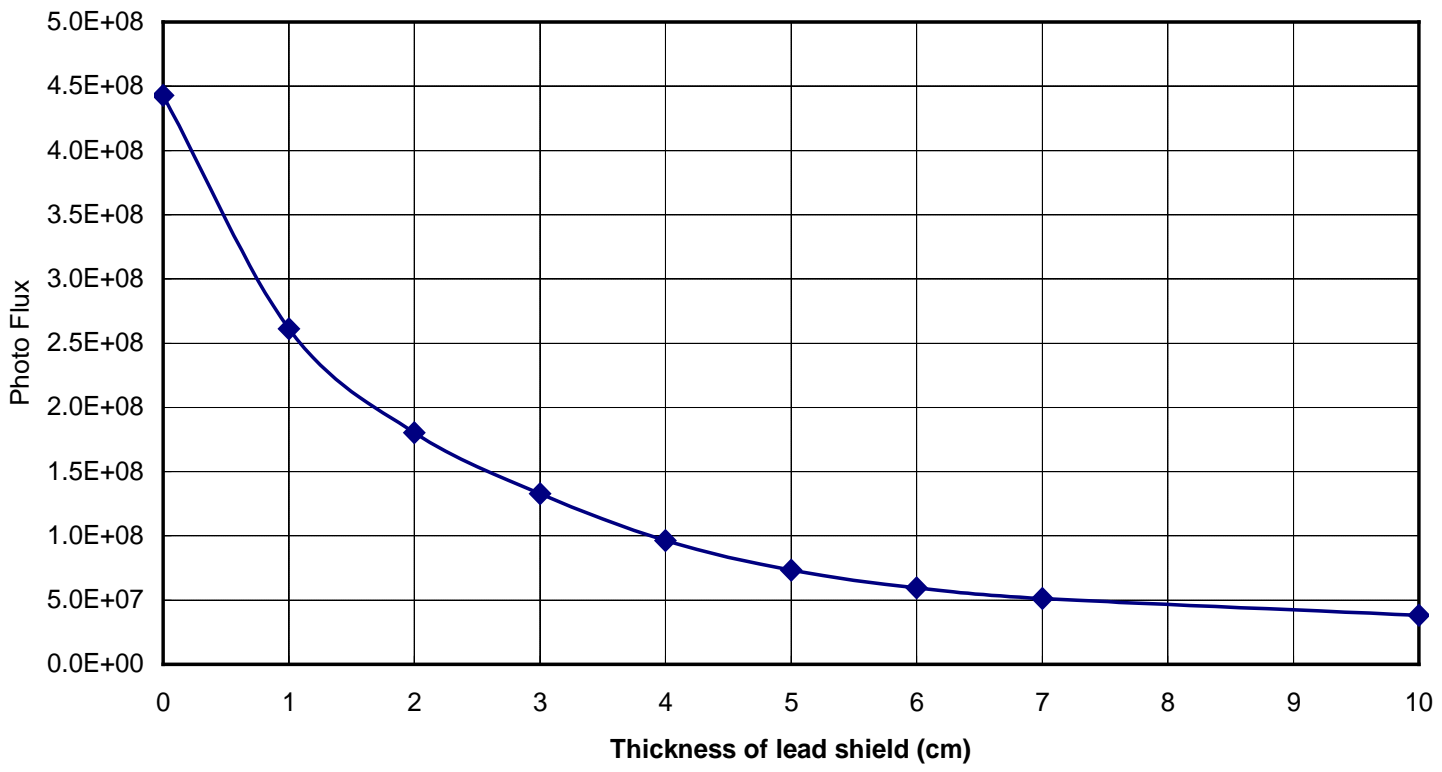

Figure 13. Gamma flux at the end of the cold neutron channel as a function of the lead shield thickness 


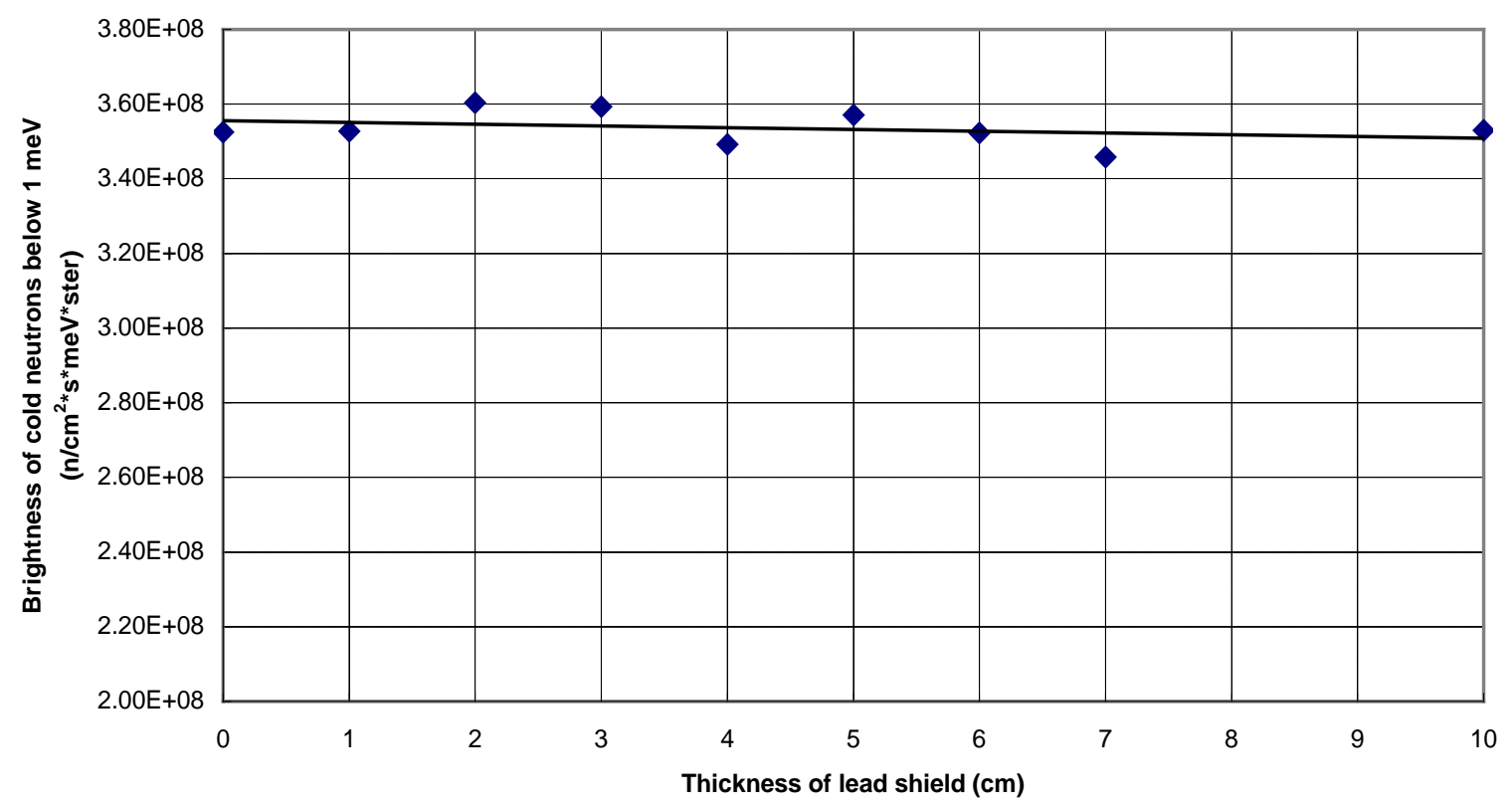

Figure 14. Cold neutron brightness as a function of the lead shield thickness

Table I. Energy deposition in the CNS bulbs for different lead shield thickness

\begin{tabular}{|c|c|c|c|c|}
\hline \multirow{2}{*}{$\begin{array}{c}\text { Thickness of lead } \\
\text { shield }\end{array}$} & \multicolumn{2}{|c|}{ Neutron Power (W) } & \multicolumn{2}{|c|}{ y Power (W) } \\
\hline & $\begin{array}{c}\text { Cold } \\
\text { moderator }\end{array}$ & Clad & $\begin{array}{c}\text { Cold } \\
\text { moderator }\end{array}$ & Clad \\
\hline $0 \mathrm{~cm}$ & $\begin{array}{c}0.134 \\
( \pm 0.56 \%) \\
\end{array}$ & $\begin{array}{c}0.0119 \\
( \pm 0.29 \%)\end{array}$ & $\begin{array}{c}0.400 \\
( \pm 0.26 \%)\end{array}$ & $\begin{array}{c}1.100 \\
( \pm 0.26 \%)\end{array}$ \\
\hline $2 \mathrm{~cm}$ & $\begin{array}{c}0.141 \\
( \pm 0.54 \%) \\
\end{array}$ & $\begin{array}{c}0.0121 \\
( \pm 0.30 \%)\end{array}$ & $\begin{array}{c}0.286 \\
( \pm 0.27 \%) \\
\end{array}$ & $\begin{array}{c}0.735 \\
( \pm 0.28 \%) \\
\end{array}$ \\
\hline $4 \mathrm{~cm}$ & $\begin{array}{r}0.149 \\
( \pm 0.52 \%) \\
\end{array}$ & $\begin{array}{c}0.0123 \\
( \pm 0.29 \%) \\
\end{array}$ & $\begin{array}{r}0.248 \\
( \pm 0.27 \%) \\
\end{array}$ & $\begin{array}{c}0.635 \\
( \pm 0.28 \%) \\
\end{array}$ \\
\hline $6 \mathrm{~cm}$ & $\begin{array}{c}0.159 \\
( \pm 0.50 \%)\end{array}$ & $\begin{array}{c}0.0125 \\
( \pm 0.29 \%)\end{array}$ & $\begin{array}{c}0.231 \\
( \pm 0.27 \%)\end{array}$ & $\begin{array}{c}0.593 \\
( \pm 0.28 \%)\end{array}$ \\
\hline $7 \mathrm{~cm}$ & $\begin{array}{c}0.164 \\
( \pm 0.49 \%)\end{array}$ & $\begin{array}{c}0.0127 \\
( \pm 0.28 \%)\end{array}$ & $\begin{array}{c}0.228 \\
( \pm 0.27 \%)\end{array}$ & $\begin{array}{c}0.585 \\
( \pm 0.28 \%) \\
\end{array}$ \\
\hline $10 \mathrm{~cm}$ & $\begin{array}{c}0.180 \\
( \pm 0.46 \%)\end{array}$ & $\begin{array}{c}0.0130 \\
( \pm 0.28 \%)\end{array}$ & $\begin{array}{c}0.224 \\
( \pm 0.27 \%)\end{array}$ & $\begin{array}{c}0.574 \\
( \pm 0.28 \%)\end{array}$ \\
\hline
\end{tabular}

\section{III.1.3 Cold Moderator Thickness}

In the CNS design, the thickness of the cold moderator is optimized to maximize the cold neutron brightness. MCNPX calculations have been performed as a function of the cold moderator Thickness. The outer radius of the cold moderator sphere fixed at $6.2 \mathrm{~cm}$ and the density of $\mathrm{LH}_{2}$ is $0.07 \mathrm{~g} / \mathrm{cm}^{3}$. The solid methane $(\mathrm{CH} 4)$ density is 0.45 $\mathrm{g} / \mathrm{cm}^{3}$, which results in hydrogen atom density of 1.6 times that of the liquid hydrogen. The thickness of the graphite column surrounding the CNS is $10 \mathrm{~cm}$. 
The brightness of the cold neutron source below $1 \mathrm{meV}$ is shown in Figure 15 through 17 for ortho- $\mathrm{LH}_{2}$, para- $\mathrm{LH}_{2}$, and solid methane as cold moderator, respectively. The MCNPX results are fitted with a polynomial functions using least square method. The optimal thickness for the $100 \%$ ortho- $\mathrm{LH}_{2}$ is $\sim 14 \mathrm{~mm}$ and the corresponding thickness for the $100 \%$ para- $-\mathrm{LH}_{2}$ is $\sim 36 \mathrm{~mm}$. The difference in the required thickness for the optimum brightness reflects the difference in the scattering cross sections of the two moderators. The optimal thickness for the solid methane is $\sim 12 \mathrm{~mm}$, which is same thickness for $100 \%$ ortho- $\mathrm{LH}_{2}$. However, the optimal neutron brightness from the solid methane is $30 \%$ higher than that of the $\mathrm{LH}_{2}$ due to the higher number density of hydrogen atoms in the solid methane.

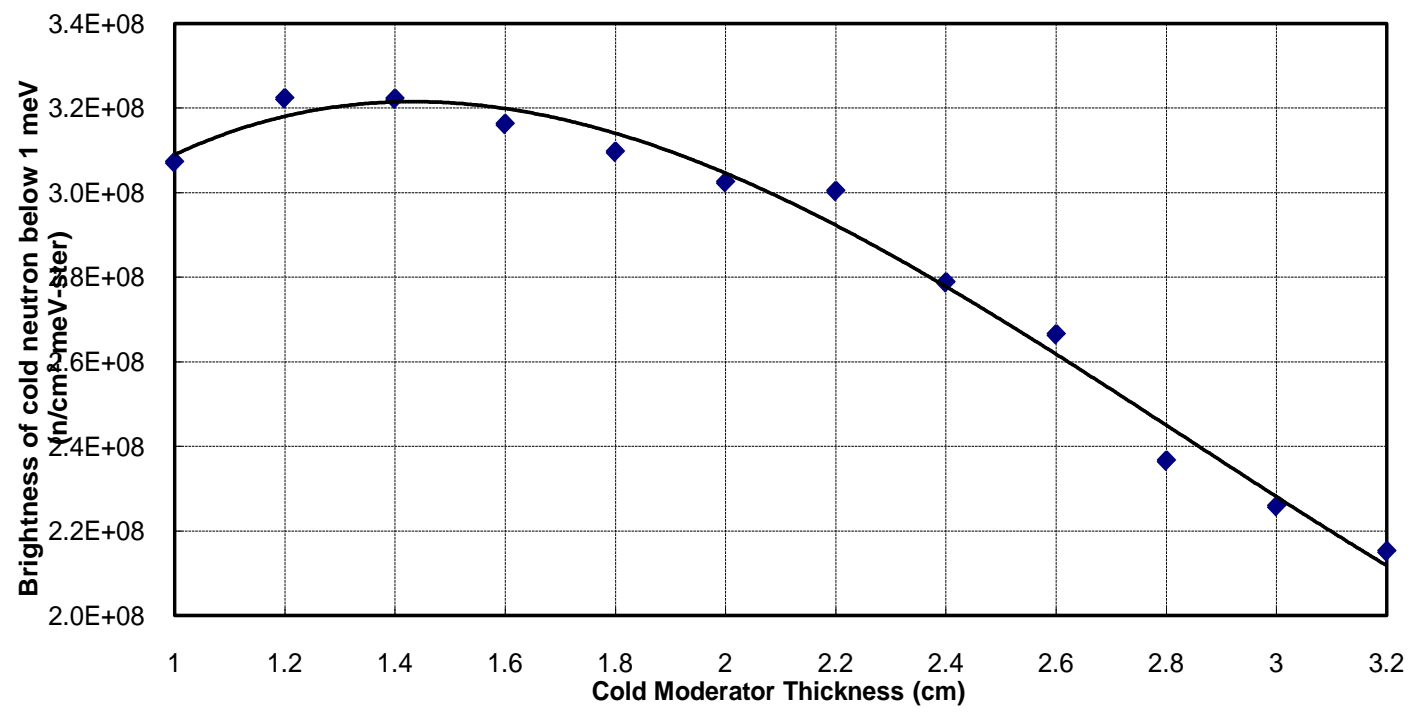

Figure 15. Cold neutron brightness as a function of the cold moderator thickness of $100 \%$ ortho- $\mathrm{LH}_{2}$ using single cold neutron source bulb and single neutron channel

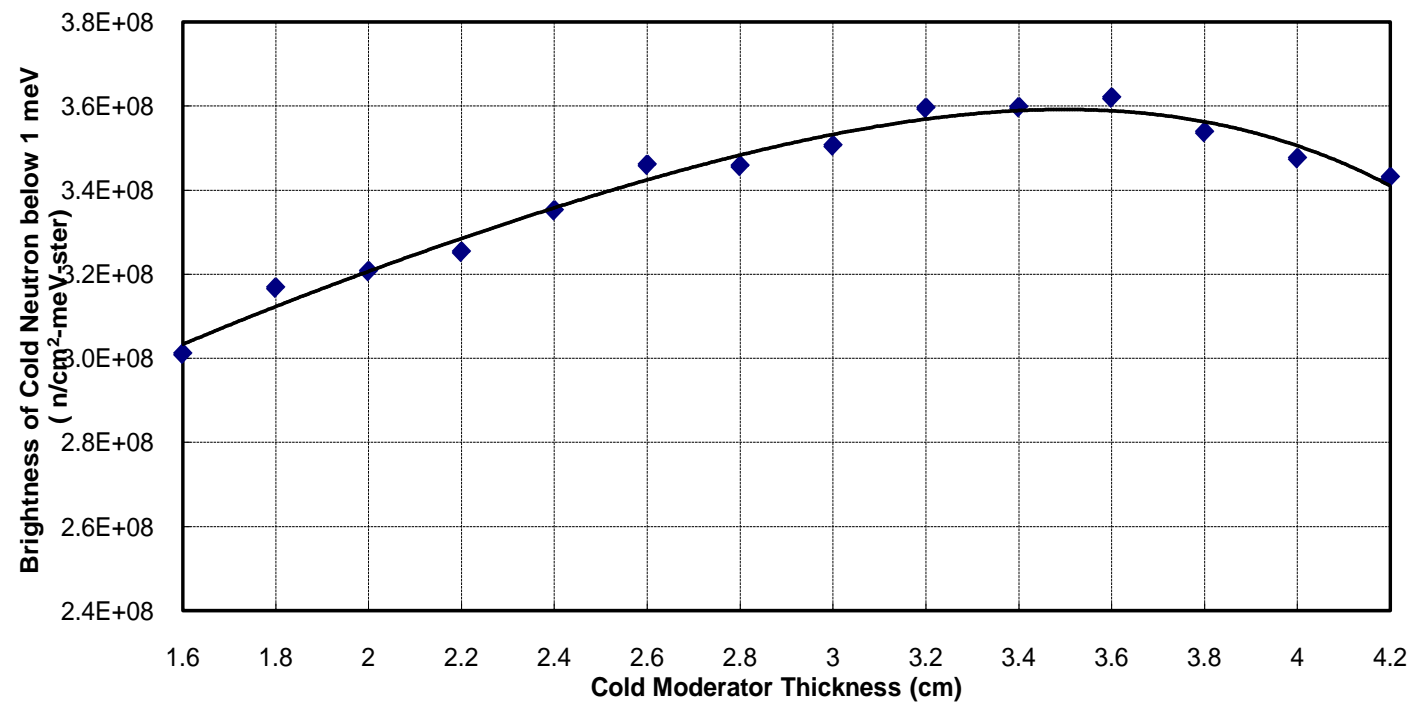

Figure 16. Cold neutron brightness as a function of the cold moderator thickness of $100 \%$ para- $\mathrm{LH}_{2}$ using single cold neutron source bulb and single neutron channel 


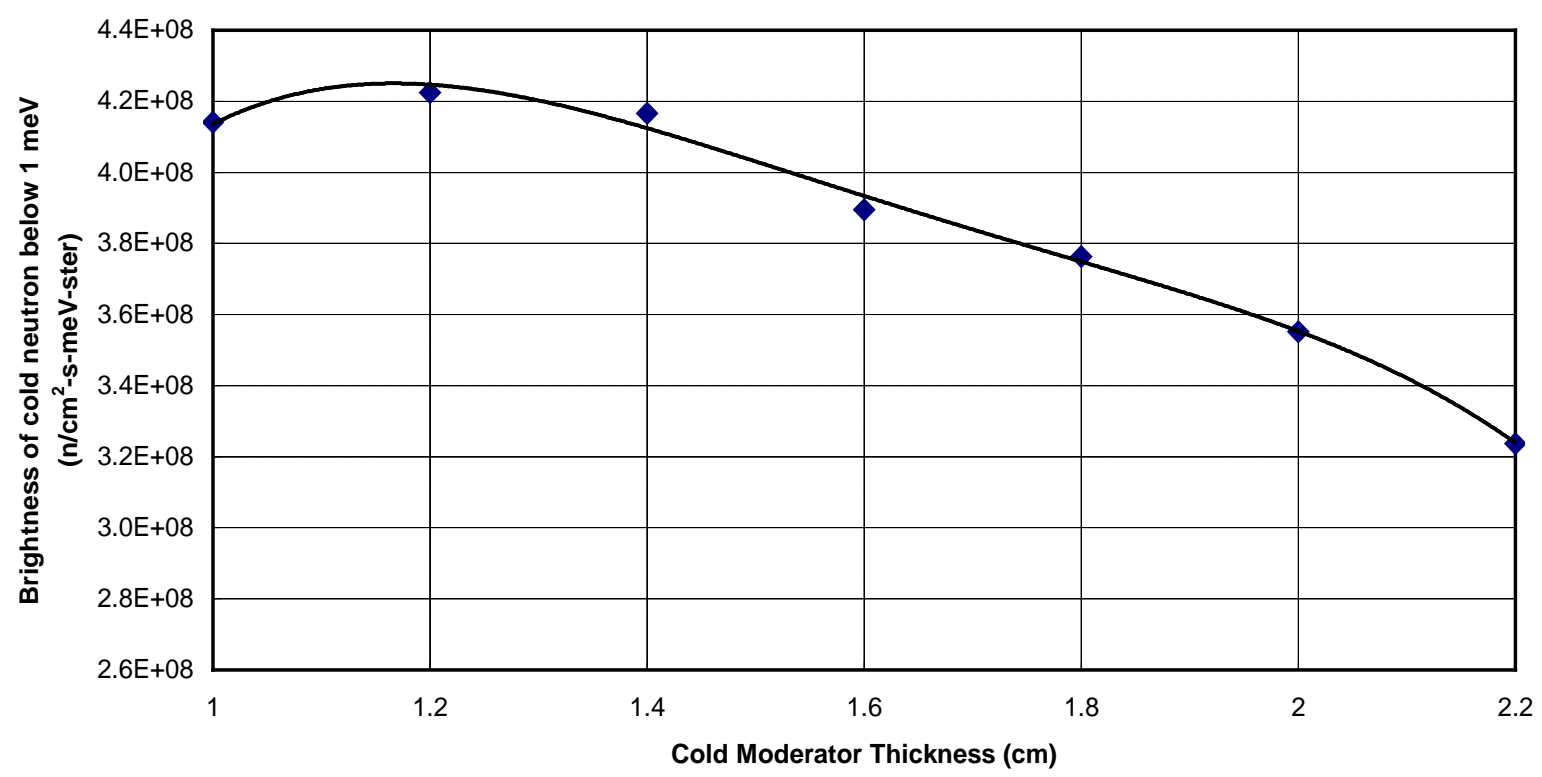

Figure 17. Cold neutron brightness as a function of the cold moderator thickness of $100 \%$ solid methane using single cold neutron source bulb and single neutron channel

\section{III.1.4 Cold Neutron Source Bulb Geometry}

The optimal thickness of each cold moderator has been determined from the previous analyses. An annular extension is added to the half sphere of the cold moderator to improve the CNS performance, as shown in Figure 18. The blue region represents the cold moderator.

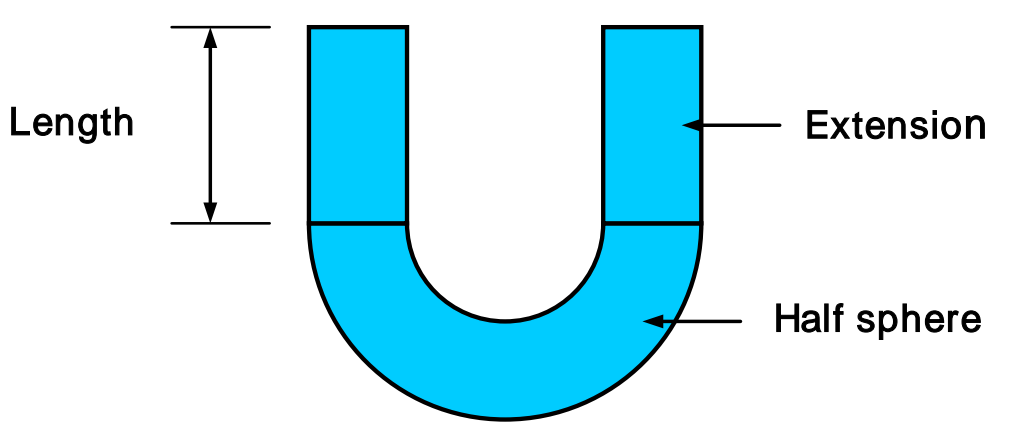

Figure 18. Geometrical configuration of the CNS bulb

Analyses have been performed to define the moderator extension length for optimum brightness using MCNPX model. The outer radius of the half sphere cold moderator is $6.2 \mathrm{~cm}$, and the para- $\mathrm{LH}_{2}$ moderator is selected with thickness of $3.6 \mathrm{~cm}$. The lead shield thickness is $5 \mathrm{~cm}$ is front of the CNS as discussed before. The obtained results are shown in Figure 19. 
The cold neutron brightness increases, saturates, and decreases as the moderator extension length of the cold moderator bulb increases. The flat range of the neutron brightness is between 2 and $5 \mathrm{~cm}$. The lower end of this range is the preferred extension value to minimize the cold moderator volume, which reduces the heat load to the cold moderator.

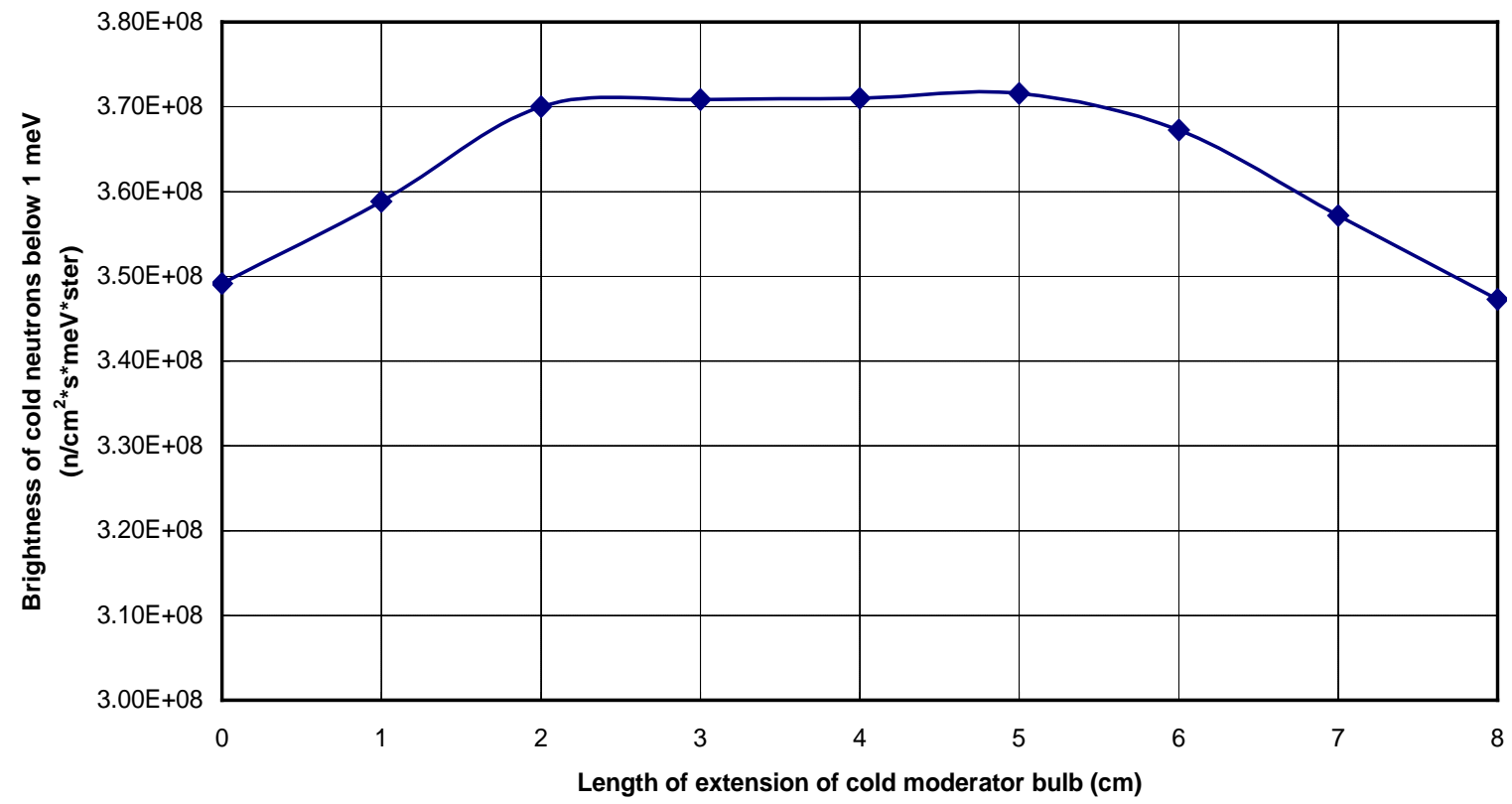

Figure 19. Cold neutron brightness as a function of the extension length of the cold moderator bulb

\section{III.1.5 Cold Moderator Gain}

The enhancement of the cold neutron brightness is calculated for the different cold moderators. The optimum thickness is used for each moderator based on the previous results. The gain results are shown in Table II. A significant cold moderator has been achieved compared with the case without cold moderator. These results can be used to select the cold moderator depend the required brightness and the cold neutron energy. 
Table II. Gain of the neutron brightness from different cold moderators

\begin{tabular}{|c|c|c|c|c|}
\hline \multirow{2}{*}{$\begin{array}{c}\text { Upper energy } \\
\text { limit }\end{array}$} & \multicolumn{4}{|c|}{ Brightness of cold neutron (n/cm²-s-meV-ster) } \\
\cline { 2 - 5 } & void & $\begin{array}{c}1.2 \mathrm{~cm} \text { of ortho- } \\
\mathrm{LH}_{2}\end{array}$ & $\begin{array}{c}3.6 \mathrm{~cm} \text { of para- } \\
\mathrm{LH}_{2}\end{array}$ & $\begin{array}{c}1.2 \mathrm{~cm} \text { of solid } \\
\text { methane }\end{array}$ \\
\hline \multirow{2}{*}{$1 \mathrm{meV}$} & $\begin{array}{c}5.24 \mathrm{e}+07 \\
( \pm 66.46 \%)\end{array}$ & $\begin{array}{c}3.22 \mathrm{e}+08 \\
( \pm 2.37 \%)\end{array}$ & $\begin{array}{c}3.59 \mathrm{e}+08 \\
( \pm 3.85 \%)\end{array}$ & $\begin{array}{c}4.22 \mathrm{e}+08 \\
( \pm 1.98 \%)\end{array}$ \\
\hline \multirow{2}{*}{$5 \mathrm{meV}$} & $\begin{array}{c}1.92 \mathrm{e}+08 \\
( \pm 18.84 \%)\end{array}$ & $\begin{array}{c}9.02 \mathrm{e}+08 \\
( \pm 0.78 \%)\end{array}$ & $\begin{array}{c}8.62 \mathrm{e}+08 \\
( \pm 2.00 \%)\end{array}$ & $1.13 \mathrm{e}+09$ \\
& $3.74 \mathrm{e}+08$ & $7.11 \mathrm{e}+08$ & $9.19 \mathrm{e}+08$ & $7.02 \mathrm{e}+08$ \\
$10 \mathrm{meV}$ & $( \pm 12.09 \%)$ & $( \pm 0.85 \%)$ & $( \pm 2.66 \%)$ & $( \pm 0.81 \%)$ \\
\hline \multirow{2}{*}{$100 \mathrm{meV}$} & $2.89 \mathrm{e}+08$ & $1.47 \mathrm{e}+08$ & $6.69 \mathrm{e}+07$ & $5.79 \mathrm{e}+07$ \\
& $( \pm 3.30 \%)$ & $( \pm 1.01 \%)$ & $( \pm 2.41 \%)$ & $( \pm 0.87 \%)$ \\
\hline
\end{tabular}

\section{III.2 Single Cold Neutron Source Bulb with Multiple Neutron Channels}

A single cold neutron source bulb with multiple cold neutron channels is an attractive design option, which provides the possibility to perform simultaneously different experiments. This design option is shown in Figure 5. The inner radius of the neutron channel is $-5.0 \mathrm{~cm}$ and the outer radius of the cold moderator sphere is $12.5 \mathrm{~cm}$. For this design, the parametric studies to define the thickness of the graphite column thickness surrounding the CNS and the lead shield thickness in front of the CNS, which have been performed for the CNS design with a single moderator bulb and a single neutron channel, are not repeated. The previous results from these studies are not expected to change for the current design option. The parametric study of the optimal thickness of cold moderator, which is expected to vary with the geometry, has been repeated for the current design option. Both, liquid hydrogen and solid methane are considered as cold moderator.

\section{III.2.1 Cold Moderator Thickness for the Single Cold Neutron Source Bulb and Multiple Neutron Channels}

Again, a parametric study was performed to find the optimal thickness of the cold moderator. A series of MCNPX calculation was carried out as a function of the cold moderator thickness, with the outer radius of the cold moderator sphere fixed at $12.5 \mathrm{~cm}$. The liquid hydrogen density is $0.07 \mathrm{~g} / \mathrm{cm}^{3}$, which is the normal density for liquid hydrogen. The corresponding value for cold solid methane is $0.45 \mathrm{~g} / \mathrm{cm}^{3}$. The thickness of graphite column surrounding the CNS is $10 \mathrm{~cm}$ as discussed before.

As shown in Figure 3, the three cold neutron channels are connected to a single cold neutron source bulb. The central neutron channel is expected to have the highest neutron flux level. The brightness of the cold neutrons below $1 \mathrm{meV}$ in the central 
channel is shown in Figure 20 through 22 for ortho- $\mathrm{LH}_{2}$, para- $\mathrm{LH}_{2}$ and solid methane respectively. The obtained results are fitted with Polynomials using the least square method to show the obtained trend. The optimum thickness is $-2.2 \mathrm{~cm}$ for ortho- $\mathrm{LH}_{2}$, $\sim 3.8 \mathrm{~cm}$ for para- $\mathrm{LH}_{2}$, and $\sim 1.6 \mathrm{~cm}$ for solid methane. These values are $\sim 0.4 \mathrm{~cm}$ larger than these obtained for the single cold neutron source with single neutron channel. The results of Figure 20 and 21 show that the cold neutron brightness of the ortho- $\mathrm{LH}_{2}$ is much higher than that of the para- $\mathrm{LH}_{2}$ for $2.2 \mathrm{~cm}$ cold moderator thickness, which are consistent with the NIST results [3]. In this design option, it should be noted that the geometrical configuration is similar to the NIST geometrical configuration. However, in the previous section of the single cold moderator bulb with single neutron channel, the obtained results were not consistent with the NIST results because of the geometrical differences. This shows that the cold neutron source performance is highly dependent on the geometrical configuration.

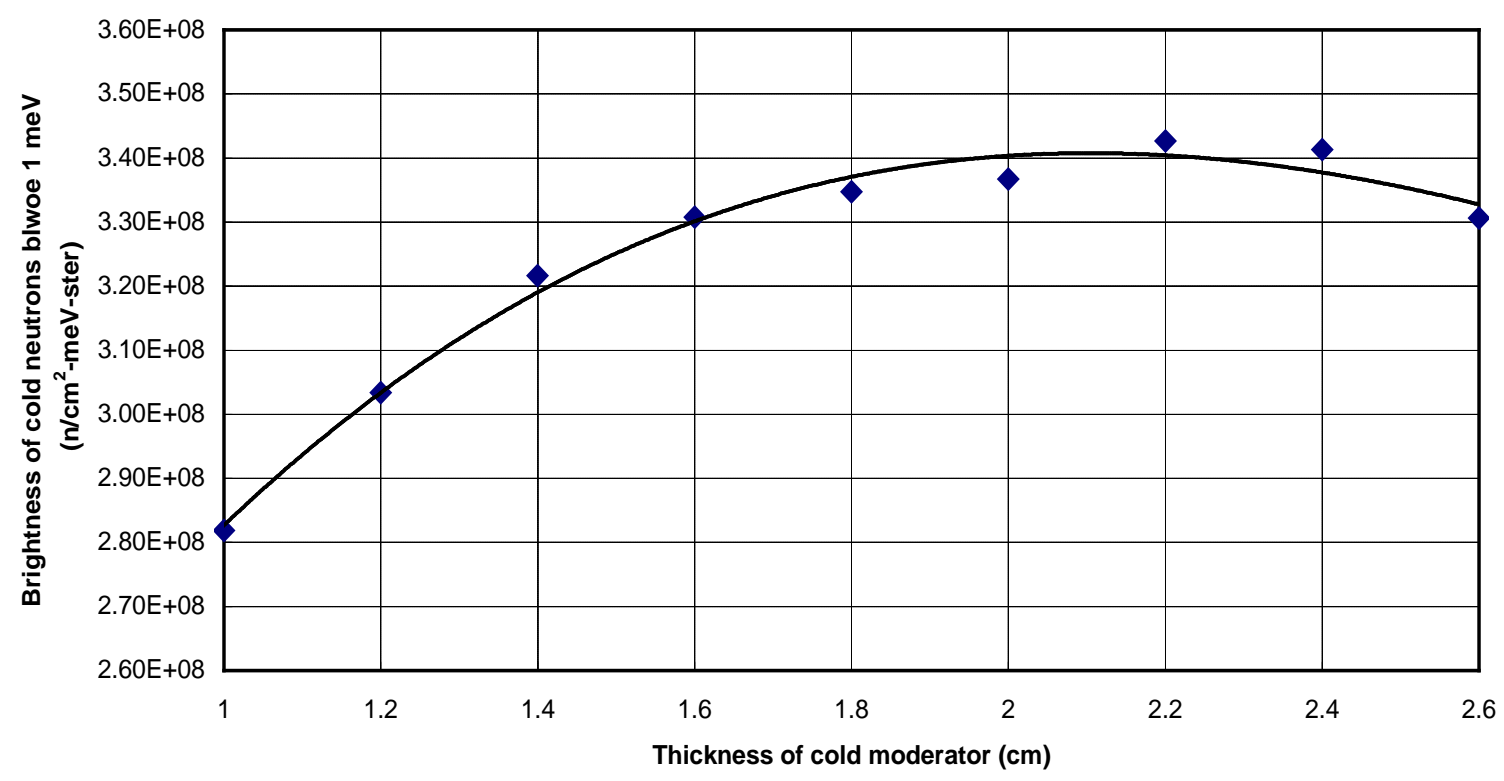

Figure 20. Cold neutron brightness from $100 \%$ ortho- $\mathrm{LH}_{2}$ as a function of the cold moderator thickness of single cold neutron source bulb with multiple neutron channels 


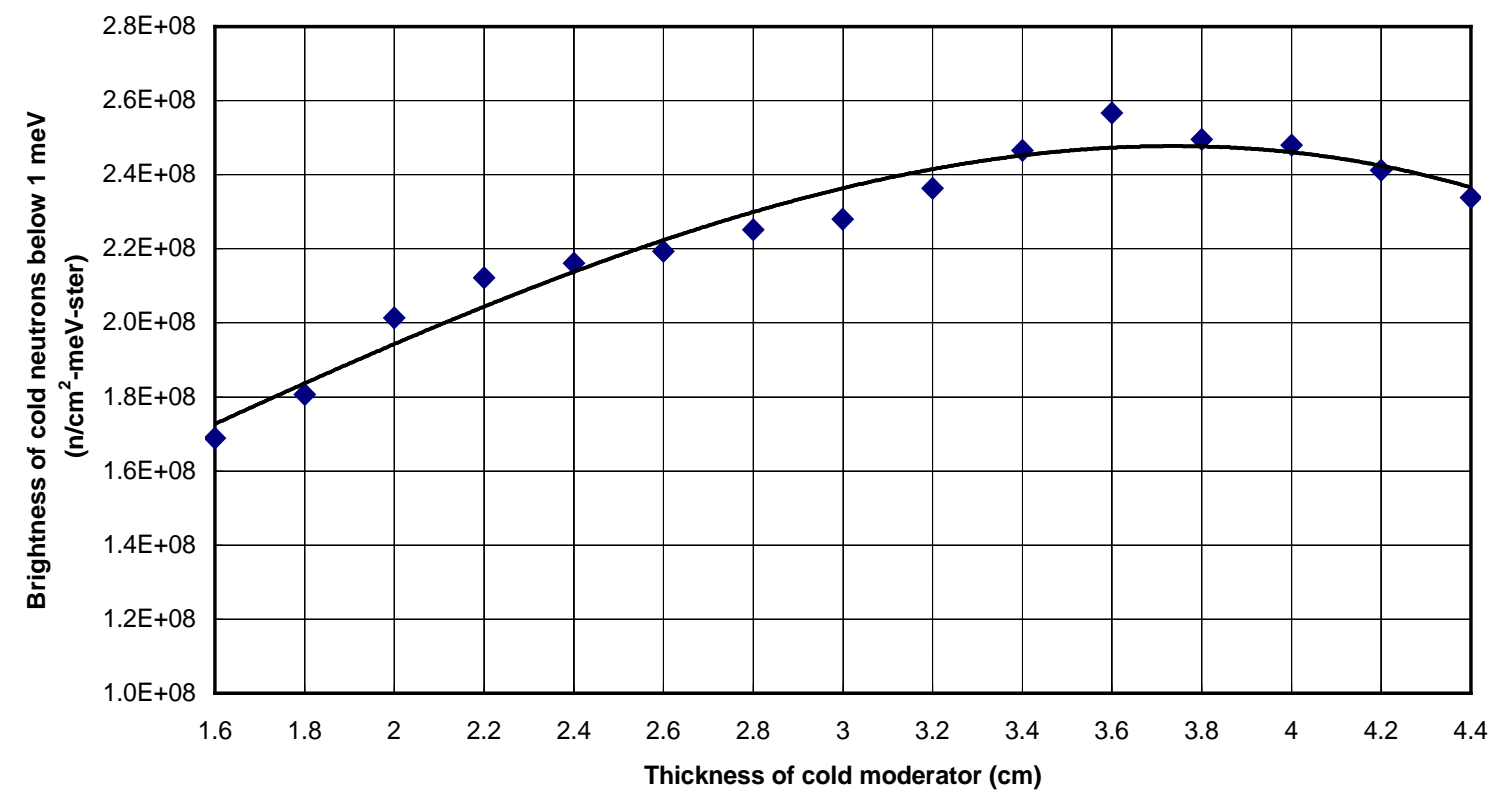

Figure 21. Cold neutron brightness from $100 \%$ para- $\mathrm{LH}_{2}$ as a function of the cold moderator thickness of single cold neutron source bulb with multiple neutron channels

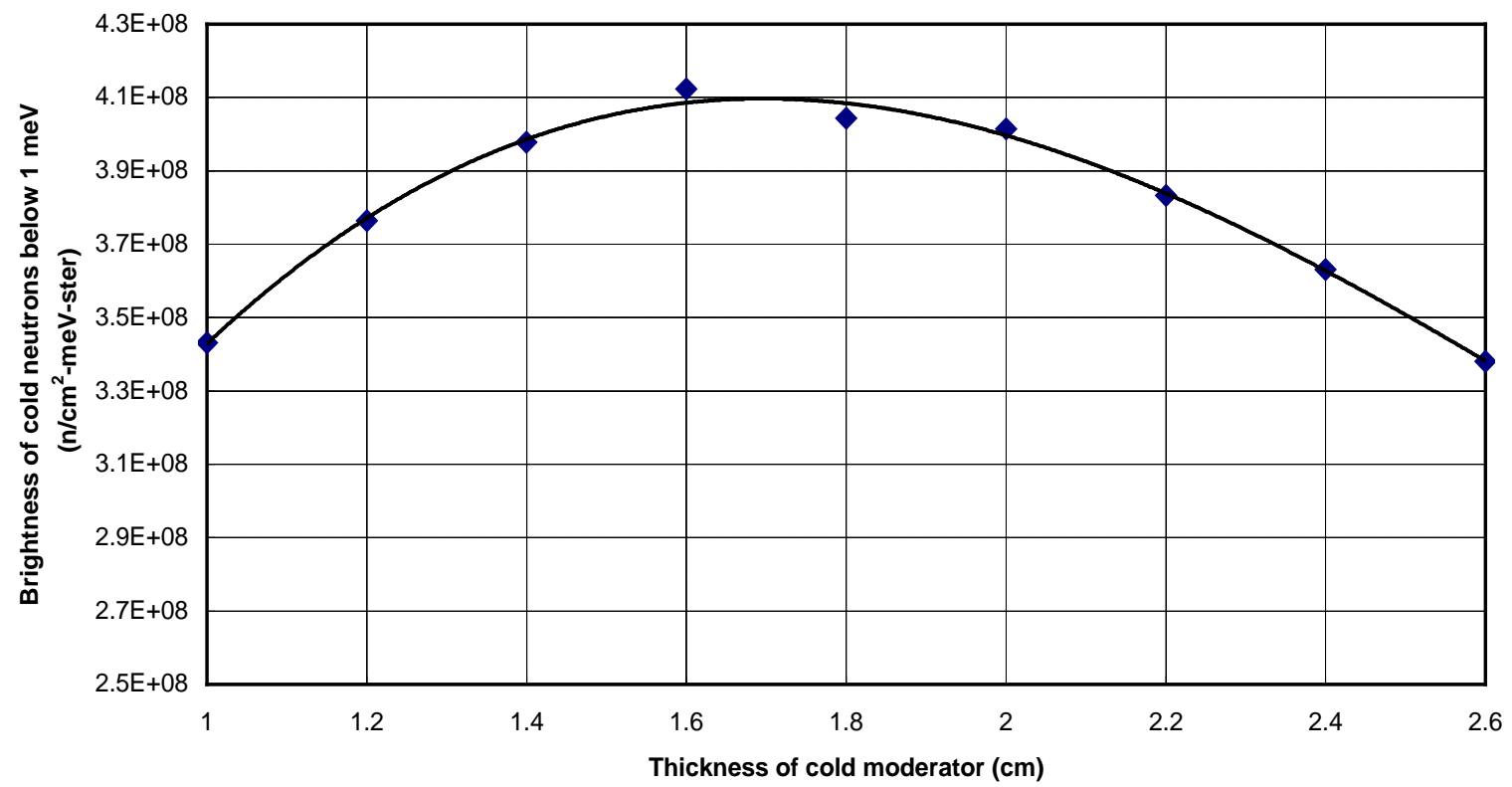

Figure 22. Cold neutron brightness from $100 \%$ methane as a function of the cold moderator thickness of single cold neutron source bulb with multiple neutron channels

\section{III.3 Multiple Cold Neutron Source Bulbs with Multiple Neutron Channels}

The geometrical configuration of the multiple cold neutron source bulbs with multiple cold neutron channels is shown in Figure 4 and 5. The geometry of each cold 
neutron source bulb and its neutron channel is similar to the first design option of section III.1. This configuration requires less space inside the water tank of the subcritical assembly for multiple cold neutron channels. In addition, different cold moderators and different cold moderator thicknesses can be used to produce the required cold neutron spectrum in each channel. The optimal thickness of the cold moderator is studied since it depends on the geometrical configuration. The interference between the cold neutron channels is analyzed. These analyses were performed for the two geometrical configurations shown in Figure 4 and 5.

\section{III.3.1 Two Cold Neutron Source Bulbs with Two Neutron Channels}

In this geometrical option, the size and geometry of the cold neutron source bulbs are the same as those of the single cold neutron bulb with single neutron channel. In addition, the graphite column thickness is $10 \mathrm{~cm}$ surrounding the two bulbs and the lead shield thickness is $5 \mathrm{~cm}$ in front of the cold neutron source as shown in Figure 23. The centerline of the two neutron channels intersect at the center of the subcritical assembly. The angle between the two centerlines is $16^{\circ}$.

The required cold moderator thickness is defined for the optimum neutron brightness for the same three moderators. The brightness of cold neutrons below $1 \mathrm{meV}$ is shown in Figure 24, through 26. The optimal thickness is about $1.4 \mathrm{~cm}$ for ortho- $\mathrm{LH}_{2}, 3.4 \mathrm{~cm}$ for para- $\mathrm{LH}_{2}$ and $1.2 \mathrm{~cm}$ for the solid methane. The optimal thickness of the cold moderators is slightly different from that of the design with the single cold neutron source bulb with single neutron channel and the cold neutron brightness is slightly lower.

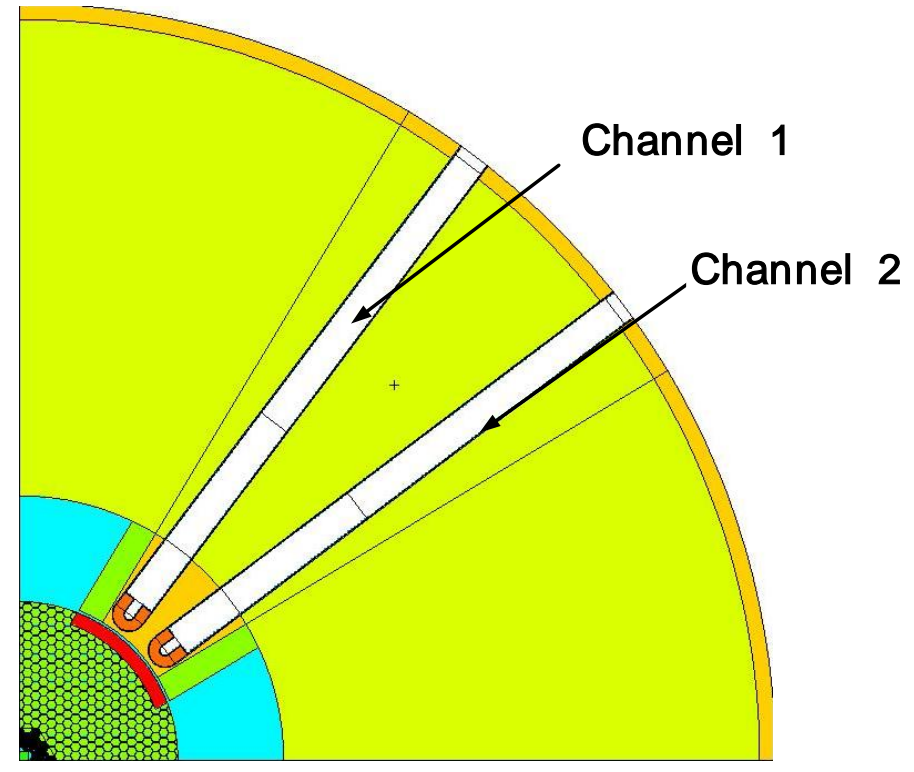

Figure 23. Geometrical configuration of two cold neutron source bulbs with two cold neutron channels 


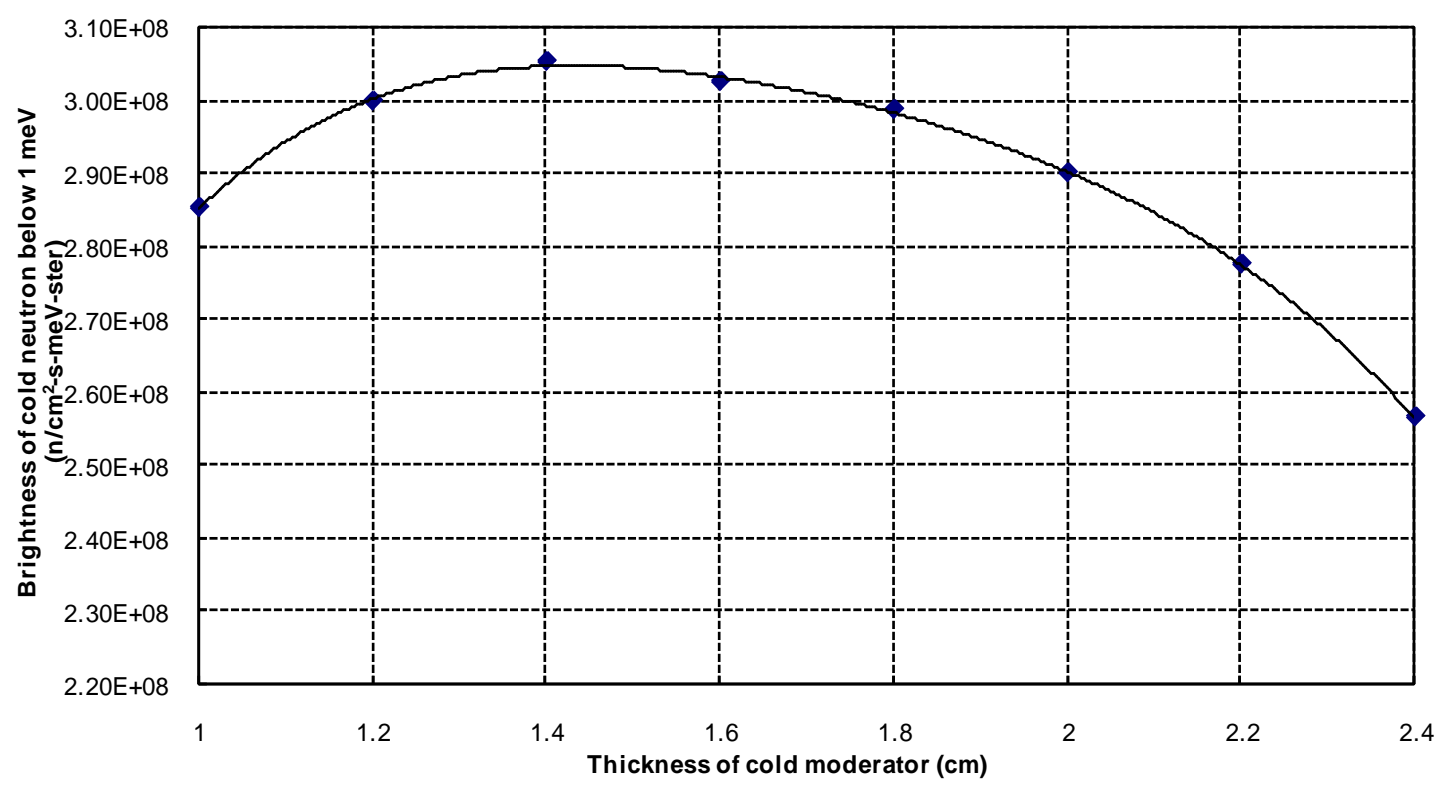

Figure 24. Cold neutron brightness from $100 \%$ ortho- $\mathrm{LH}_{2}$ as a function of the cold moderator thickness for design with two cold neutron source bulbs and two neutron channels

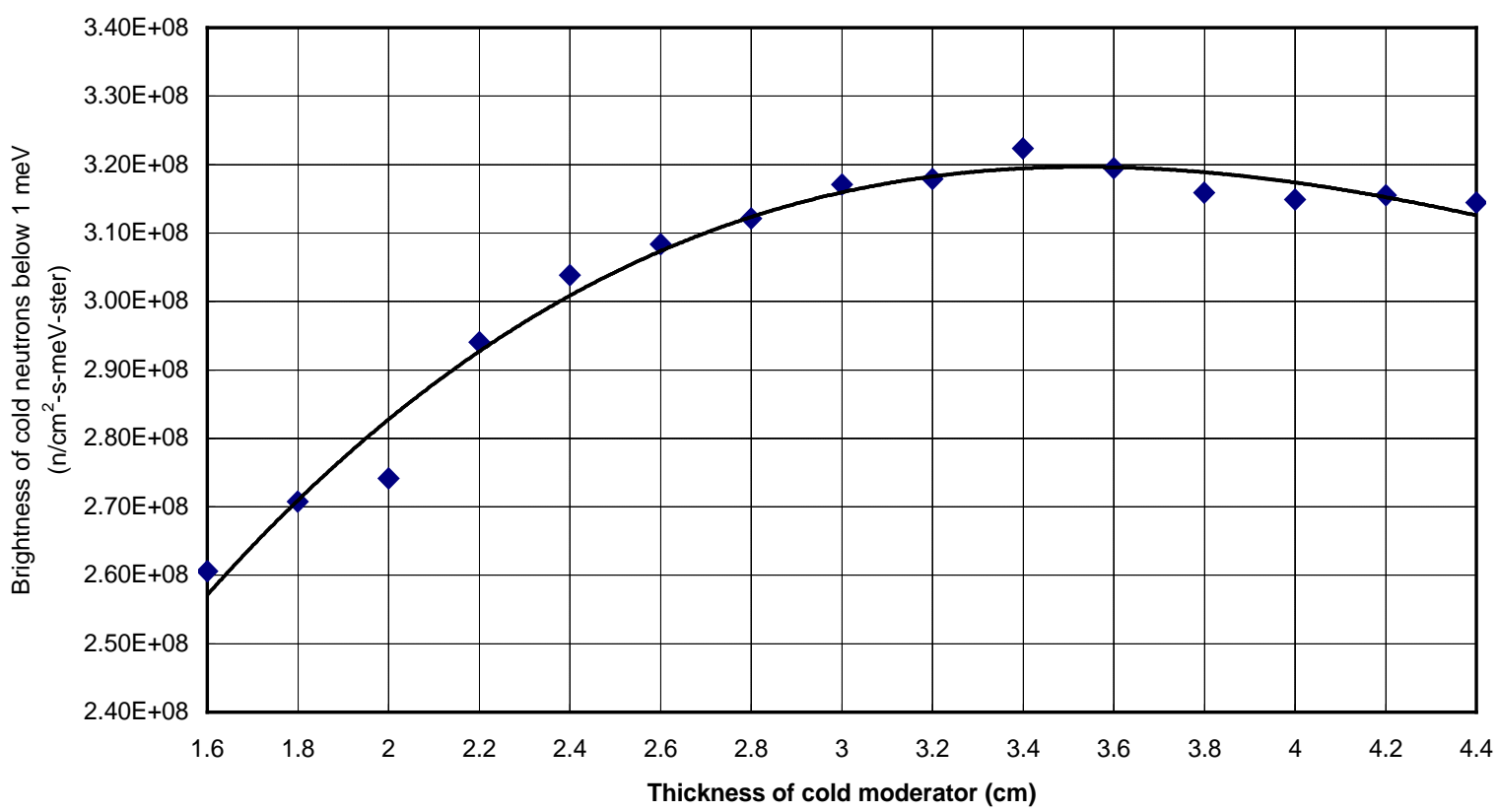

Figure 25. Cold neutron brightness from $100 \%$ para- $\mathrm{LH}_{2}$ as a function of the cold moderator thickness for design with two cold neutron source bulbs and two neutron channels 


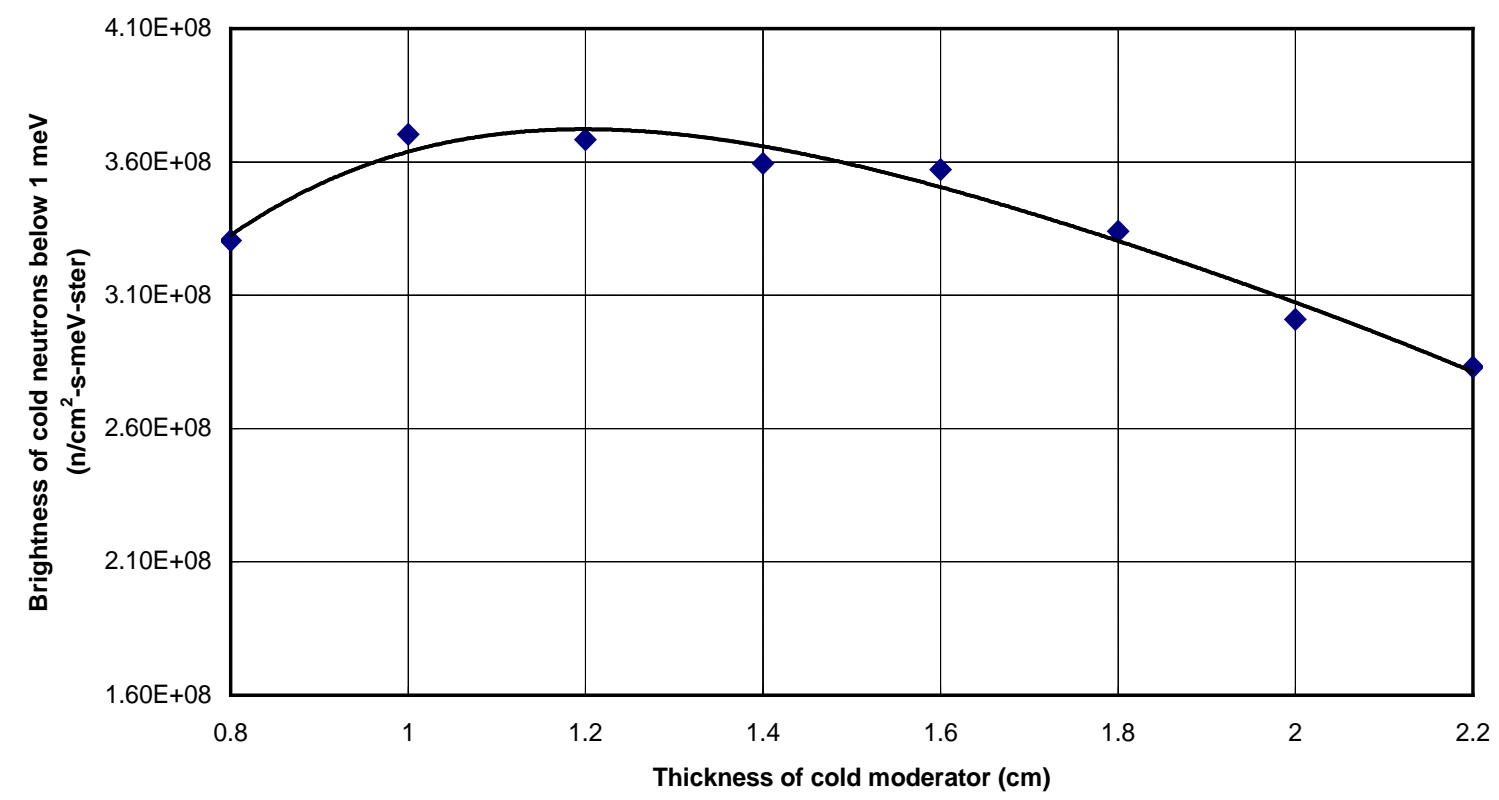

Figure 26. Cold neutron brightness from $100 \%$ solid methane as a function of the cold moderator thickness for design with two cold neutron source bulbs and two neutron channels

\section{III.3.2 Three Cold Neutron Source Bulbs with Three Neutron Channels}

In this design option, the geometry and the dimensions of the cold neutron bulb are the same as before. In addition, the graphite and the lead thickness are kept without change. The optimal cold moderator thickness of this geometry is defined for the three moderators. The geometry of this configuration is shown in Figure 27.

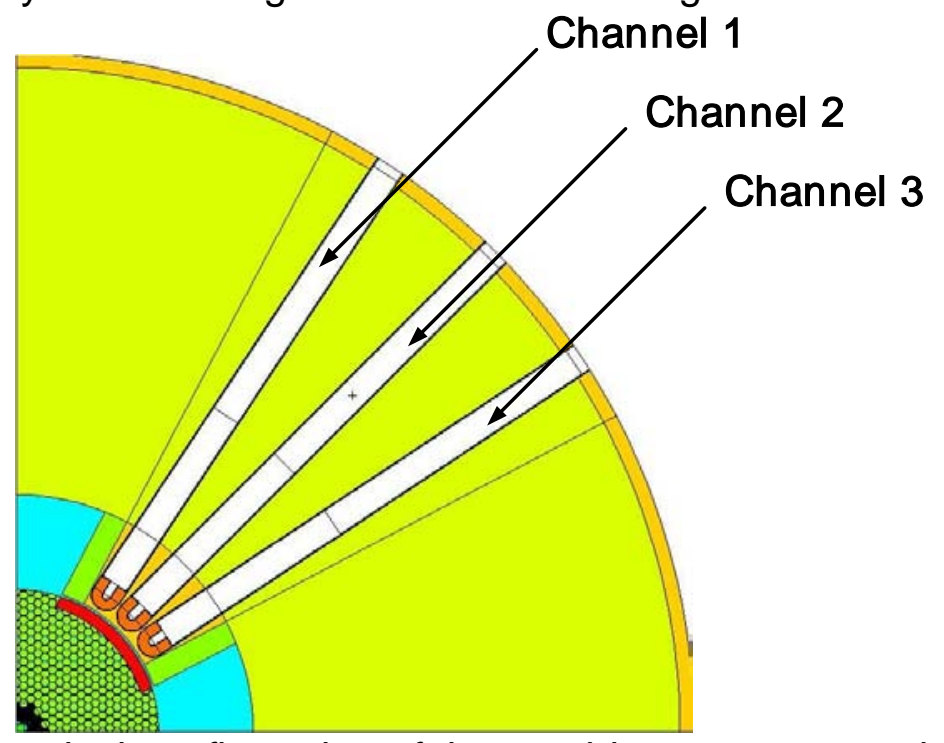

Figure 27. Geometrical configuration of three cold neutron source bulbs with three cold neutron channels 
The brightness of cold neutrons below $1 \mathrm{meV}$ is shown in Figure 28 through 30 for the three moderators. The optimal thickness is $-1.6 \mathrm{~cm}$ for ortho- $\mathrm{LH}_{2},-3.6 \mathrm{~cm}$ for para$\mathrm{LH}_{2}$ and $\sim 1.0 \mathrm{~cm}$ for solid methane. Compared to the single cold neutron source bulb, the cold neutron brightness is lower.

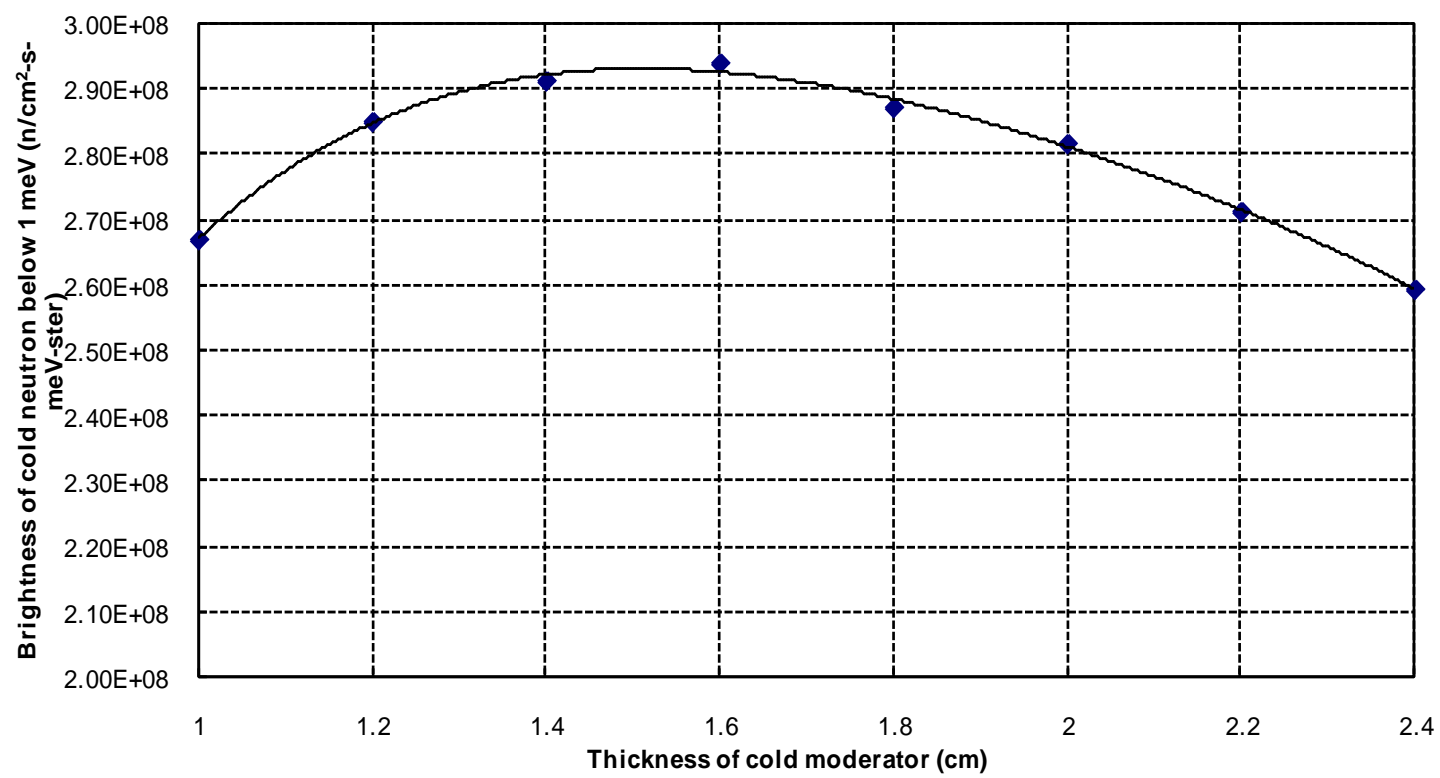

Figure 28. Cold neutron brightness from $100 \%$ ortho- $\mathrm{LH}_{2}$ as a function of the cold moderator thickness for design with three cold neutron source bulbs and three neutron channels

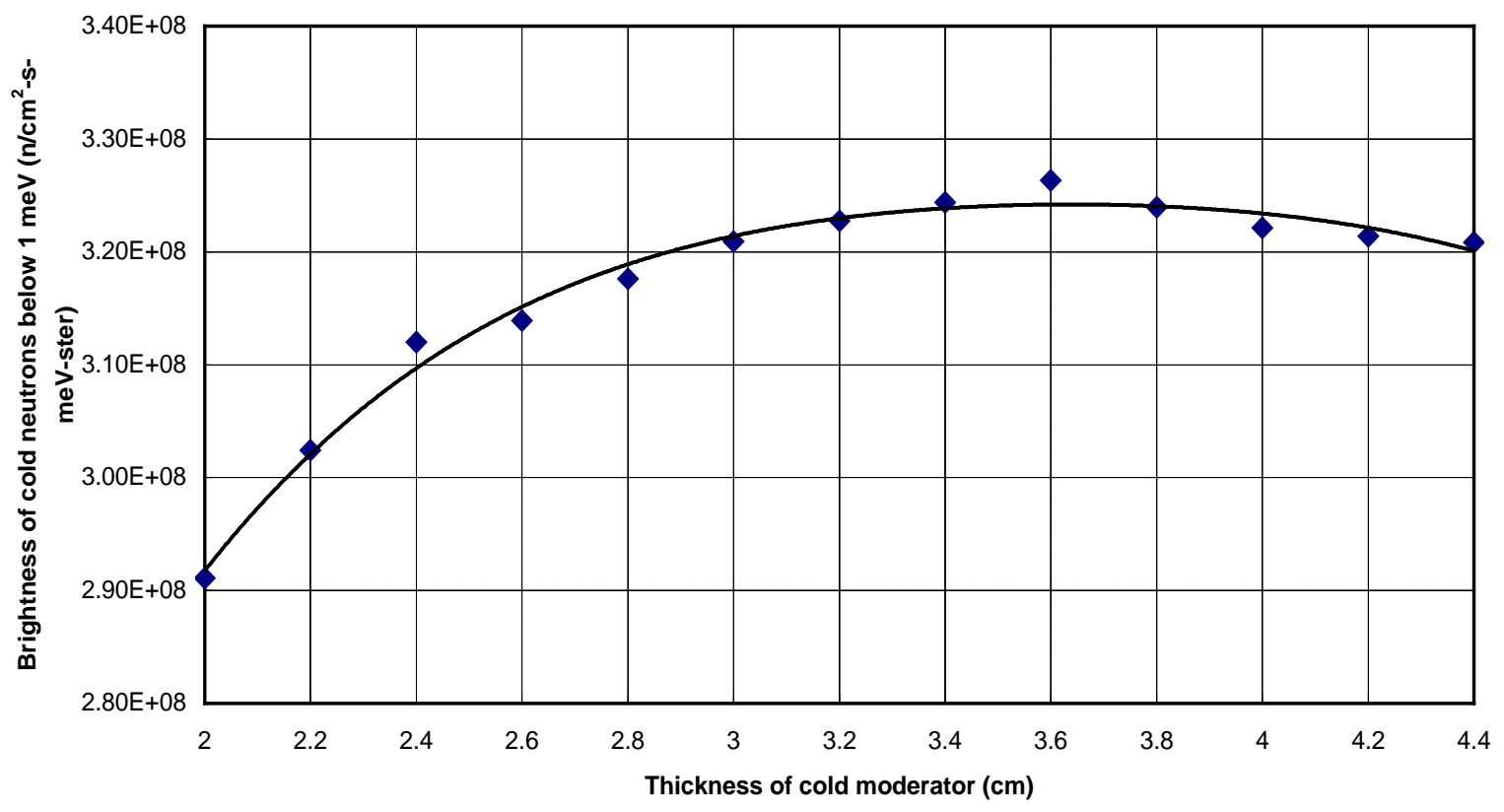

Figure 29. Neutron brightness from $100 \%$ para- $-\mathrm{LH}_{2}$ as a function of the cold moderator thickness for design with three cold neutron source bulbs and three neutron channels 


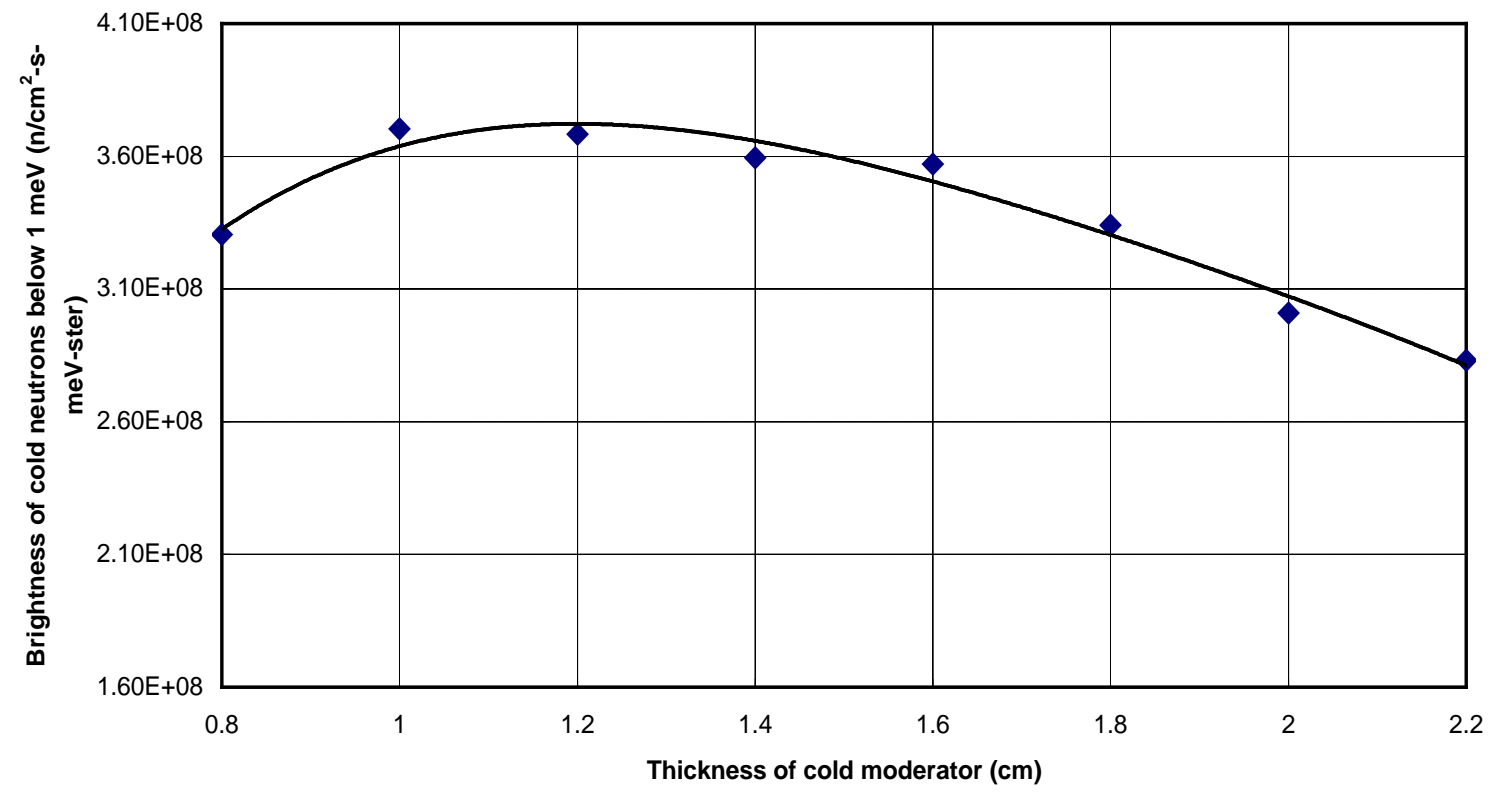

Figure 30 . Neutron brightness from $100 \%$ sold methane as a function of the cold moderator thickness for design with three cold neutron source bulbs and three neutron channels

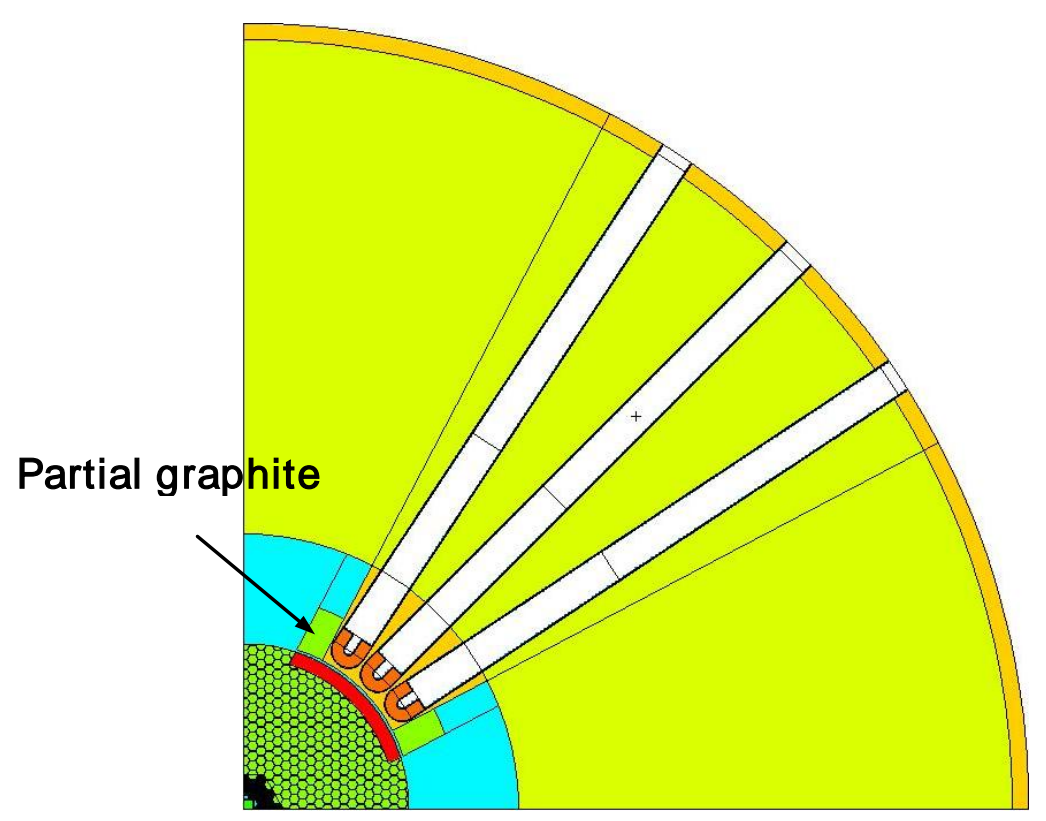

Figure 31. Geometrical configuration of three cold neutron source bulbs with three cold neutron channels and reduced radial graphite thickness

For this configuration, the effect of the radial graphite column length on the neutron brightness is examined for the $100 \%$ para- $\mathrm{LH}_{2}$ cold moderator. The radial graphite length is reduced from 40 to $18 \mathrm{~cm}$ as shown in Figure 31, compared with the 
configuration shown in Figure 27. The cold moderator thickness is $3.6 \mathrm{~cm}$. The obtained cold neutron brightness is given Table III for the two thicknesses. The reduction in the graphite thickness reduces the cold neutron brightness by less than $10 \%$. However, the design with partial graphite column length simplifies the mechanical design.

Table III Cold neutron brightness for two different radial graphite length with $100 \%$ para- $\mathrm{LH}_{2}$ cold moderator

\begin{tabular}{|c|c|c|}
\hline \multirow{2}{*}{$\begin{array}{c}\text { Upper Neutron } \\
\text { Energy, meV }\end{array}$} & \multicolumn{2}{|c|}{ Brightness of cold neutron (n/cm ${ }^{2}$-s-meV-ster) } \\
\cline { 2 - 3 } & Full graphite column & Partial graphite column \\
\hline \multirow{2}{*}{1} & $\begin{array}{c}3.26 \mathrm{e}+08 \\
( \pm 4.89 \%)\end{array}$ & $\begin{array}{c}2.95 \mathrm{e}+08 \\
( \pm 2.59 \%)\end{array}$ \\
\hline \multirow{2}{*}{5} & $7.78 \mathrm{e}+08$ & $7.11 \mathrm{e}+08$ \\
& $( \pm 2.25 \%)$ & $( \pm 1.85 \%)$ \\
\hline \multirow{2}{*}{10} & $7.99 \mathrm{e}+08$ & $7.63 \mathrm{e}+08$ \\
& $( \pm 2.81 \%)$ & $( \pm 2.97 \%)$ \\
\multirow{2}{*}{100} & $6.06 \mathrm{e}+07$ & $5.50 \mathrm{e}+07$ \\
& $( \pm 2.62 \%)$ & $( \pm 2.54 \%)$ \\
\hline
\end{tabular}

\section{III.3.3 Neutron Brightness Changes Due to the Use of Multiple Cold Neutron Channels}

Analyses were carried out to define the impact of using multiple cold neutron channels on the obtained neutron brightness. Three calculational models are used, single cold neutron source bulb with single cold neutron channel, two cold neutron source bulbs with two cold neutron channels, and three cold neutron source bulbs with three cold neutron channels as shown in Figure 32. The geometry and the dimensions of the cold neutron bulbs are the same. The cold moderator is $100 \%$ para- $\mathrm{LH}_{2}$ and its thickness is $3.6 \mathrm{~cm}$.

The cold neutron brightness is shown in Table IV for the three configurations. The change in the neutron brightness is $-10 \%$ relative to the single cold neutron source bulb with single neutron channel. The extra capability from the multiple cold neutron channels over compensate for this small variation in the cold neutron brightness. 


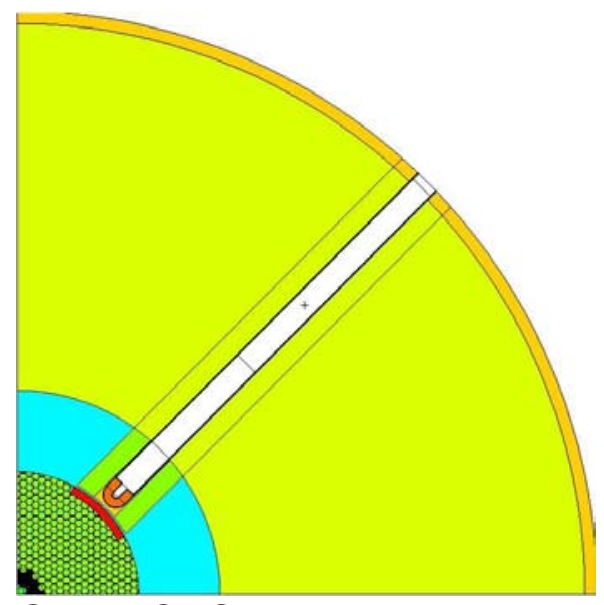

Single CNS with single neutron channel

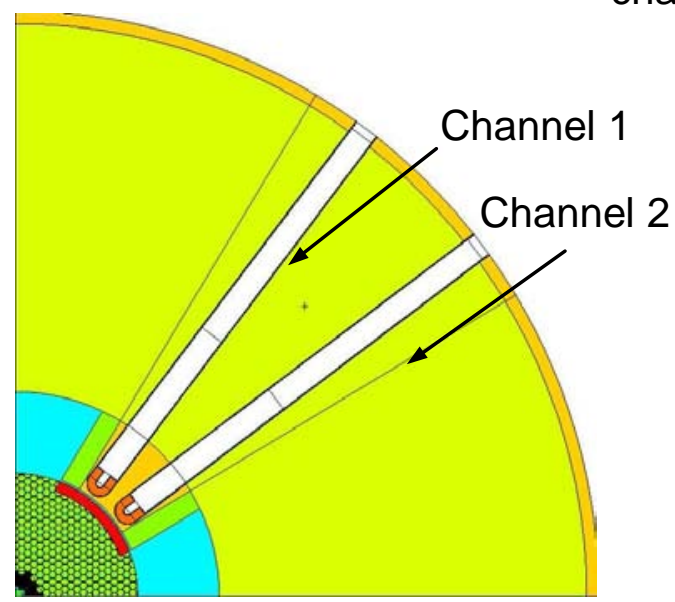

Two CNS with two neutron channel

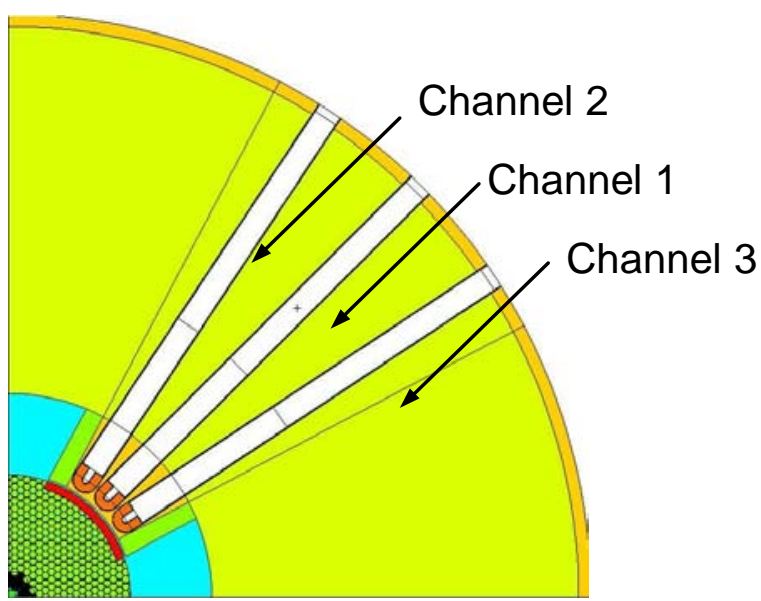

Three CNS with three neutron channel

Figure 32. Calculational models for studying multiple cold neutron channels

Table IV. Cold neutron source brightness for multiple cold neutron channels

\begin{tabular}{|c|c|c|c|c|c|c|}
\hline \multirow{2}{*}{$\begin{array}{c}\text { Upper } \\
\text { energy } \\
\text { limit, meV }\end{array}$} & \multicolumn{5}{|c|}{$\begin{array}{c}\text { Single CNS } \\
\text { and single } \\
\text { channel }\end{array}$} & \multicolumn{2}{|c|}{$\begin{array}{c}\text { Two CNS and two } \\
\text { channels }\end{array}$} & \multicolumn{2}{|c|}{ Three CNS and three channels } \\
\cline { 3 - 7 } & Channel 1 & Channel 2 & Channel 1 & Channel 2 & Channel 3 \\
\hline \multirow{2}{*}{1} & $3.59 \mathrm{e}+08$ & $3.19 \mathrm{e}+08$ & $3.16 \mathrm{e}+08$ & $3.25 \mathrm{e}+08$ & $3.04 \mathrm{e}+08$ & $3.07 \mathrm{e}+08$ \\
& $( \pm 3.85 \%)$ & $( \pm 2.52 \%)$ & $( \pm 3.36 \%)$ & $( \pm 4.89 \%)$ & $( \pm 7.82 \%)$ & $( \pm 2.59 \%)$ \\
\hline \multirow{2}{*}{5} & $8.62 \mathrm{e}+08$ & $8.10 \mathrm{e}+08$ & $7.83 \mathrm{e}+08$ & $7.78 \mathrm{e}+08$ & $7.17 \mathrm{e}+08$ & $7.74 \mathrm{e}+08$ \\
& $( \pm 2.00 \%)$ & $( \pm 2.21 \%)$ & $( \pm 2.08 \%)$ & $( \pm 2.25 \%)$ & $( \pm 2.09 \%)$ & $( \pm 2.21 \%)$ \\
\hline \multirow{2}{*}{10} & $9.19 \mathrm{e}+08$ & $8.28 \mathrm{e}+08$ & $7.91 \mathrm{e}+08$ & $7.99 \mathrm{e}+08$ & $7.86 \mathrm{e}+08$ & $7.71 \mathrm{e}+08$ \\
& $( \pm 2.66 \%)$ & $( \pm 2.66 \%)$ & $( \pm 2.53 \%)$ & $( \pm 2.81 \%)$ & $( \pm 3.08 \%)$ & $( \pm 2.65 \%)$ \\
\hline \multirow{2}{*}{100} & $6.69 \mathrm{e}+07$ & $6.24 \mathrm{e}+07$ & $5.93 \mathrm{e}+07$ & $6.06 \mathrm{e}+07$ & $5.57 \mathrm{e}+07$ & $5.83 \mathrm{e}+07$ \\
& $( \pm 2.41 \%)$ & $( \pm 2.36 \%)$ & $( \pm 2.34 \%)$ & $( \pm 2.62 \%)$ & $( \pm 2.70 \%)$ & $( \pm 2.44 \%)$ \\
\hline
\end{tabular}




\section{Energy Deposition in the Cold Moderator}

In the previous section, different cold neutron source designs have been studied to define the neutron brightness. In addition, the nuclear energy deposition in the cold moderator has been calculated to define the size of cryogenic cooling system. The optimal designs determined in the previous section have been used. The energy deposition in the cold neutron bulbs for the configurations shown in Figure 2, 4, and 5 are given in Table $\mathrm{V}$ for para- $\mathrm{LH}_{2}$, ortho- $\mathrm{LH}_{2}$ and solid methane cold moderators. The optimal thickness of each cold moderator is used. In all the configurations, $5 \mathrm{~cm}$ of lead shield is used in front of the cold neutron source.

The results show that the photon heating is factor of 5 to 10 larger than the neutron heating. Such result is expected since the neutron energy is very low relative to the photon energy. Analyses have been performed to determine the impact of the electron energy on the cold neutron source parameters. All the previous analyses used $100 \mathrm{KW}$ electron beam with $100 \mathrm{MeV}$ electrons. Previous work showed that the neutron yield and neutron flux level is not sensitive to the electron energy in the range of 100 to $200 \mathrm{MeV}$ [1]. However, as the electron energy increases, the energy of the generated photons increases. The analyses of the cold neutron source with single moderator bulb and single neutron channel has been analyzed with $200 \mathrm{MeV}$ electrons to compare with $100 \mathrm{MeV}$ electrons. The lead shield thickness is $5 \mathrm{~cm}$ and the para- $\mathrm{LH}_{2}$ moderator thickness is $3.6 \mathrm{~cm}$. The comparison of the results is given in table VIII where is shows an insignificant effect.

Table V. Nuclear energy deposition in the cold neutron source configuration with single moderator bulb and single neutron channel

\begin{tabular}{|c|c|c|c|c|c|}
\hline $\begin{array}{c}\text { Cold } \\
\text { moderator } \\
\text { material }\end{array}$ & $\begin{array}{c}\text { Cold } \\
\text { moderator } \\
\text { thickness, } \\
\mathrm{cm}\end{array}$ & $\begin{array}{c}\text { Cold } \\
\text { moderator } \\
\text { mass, } \mathrm{g}\end{array}$ & $\begin{array}{c}\text { Neutron } \\
\text { brightness below } \\
1 \mathrm{meV}, \\
\mathrm{n} / \mathrm{cm}^{2} \cdot \mathrm{s} \cdot \mathrm{meV} \cdot \mathrm{ster}\end{array}$ & $\begin{array}{c}\text { Neutron } \\
\text { heating, W }\end{array}$ & $\begin{array}{c}\text { Photon } \\
\text { heating, W }\end{array}$ \\
\hline Para-LH & 3.6 & 71.718 & $\begin{array}{c}3.59 \mathrm{e}+08 \\
( \pm 3.85 \%)\end{array}$ & $\begin{array}{c}0.158 \\
( \pm 0.51 \%)\end{array}$ & $\begin{array}{c}0.826 \\
( \pm 0.28 \%)\end{array}$ \\
\hline Ortho-LH 2 & 1.2 & 33.296 & $\begin{array}{c}3.24 \mathrm{e}+08 \\
( \pm 2.34 \%)\end{array}$ & $\begin{array}{c}0.098 \\
( \pm 0.50 \%)\end{array}$ & $\begin{array}{c}0.918 \\
( \pm 0.28 \%)\end{array}$ \\
\hline $\begin{array}{c}\text { Solid } \\
\text { methane }\end{array}$ & 1.2 & 215.530 & $\begin{array}{c}4.36 \mathrm{e}+08 \\
( \pm 1.95 \%)\end{array}$ & $\begin{array}{c}0.138 \\
( \pm 0.51 \%)\end{array}$ & $\begin{array}{c}1.350 \\
( \pm 0.28 \%)\end{array}$ \\
\hline
\end{tabular}


Table VI. Nuclear energy deposition in the cold neutron source configuration with two moderator bulbs and two neutron channels

\begin{tabular}{|c|c|c|c|c|c|}
\hline $\begin{array}{c}\text { Cold } \\
\text { moderator } \\
\text { material }\end{array}$ & $\begin{array}{c}\text { Cold } \\
\text { moderator } \\
\text { thickness, } \\
\mathrm{cm}\end{array}$ & $\begin{array}{c}\text { Cold } \\
\text { moderator } \\
\text { mass, } \mathrm{g}\end{array}$ & $\begin{array}{c}\text { Neutron brightness } \\
\text { below } 1 \mathrm{meV}, \\
\mathrm{n} / \mathrm{cm}^{2} \cdot \mathrm{s} \cdot \mathrm{meV} \cdot \mathrm{ster}\end{array}$ & $\begin{array}{c}\text { Neutron } \\
\text { heating, W }\end{array}$ & $\begin{array}{c}\text { Photon } \\
\text { heating, W }\end{array}$ \\
\hline para-LH 2 & 3.4 & 139.465 & $\begin{array}{c}3.22 \mathrm{e}+08 \\
( \pm 2.52 \%)\end{array}$ & $\begin{array}{c}0.336 \\
( \pm 0.39 \%)\end{array}$ & $\begin{array}{c}2.189 \\
( \pm 0.26 \%)\end{array}$ \\
\hline ortho-LH 2 & 1.4 & 75.685 & $\begin{array}{c}3.05 \mathrm{e}+08 \\
( \pm 2.43 \%)\end{array}$ & $\begin{array}{c}0.232 \\
( \pm 0.38 \%)\end{array}$ & $\begin{array}{c}2.278 \\
( \pm 0.26 \%)\end{array}$ \\
\hline $\begin{array}{c}\text { solid } \\
\text { methane }\end{array}$ & 1.2 & 431.06 & $\begin{array}{c}3.88 \mathrm{e}+08 \\
( \pm 2.05 \%)\end{array}$ & $\begin{array}{c}0.297 \\
( \pm 0.39 \%)\end{array}$ & $\begin{array}{c} \pm .113 \\
( \pm 0.26 \%)\end{array}$ \\
\hline
\end{tabular}

Table VII. Nuclear energy deposition in the cold neutron source configuration with three moderator bulbs and three neutron channels

\begin{tabular}{|c|c|c|c|c|c|}
\hline $\begin{array}{c}\text { Cold } \\
\text { moderator } \\
\text { material }\end{array}$ & $\begin{array}{c}\text { Cold } \\
\text { moderator } \\
\text { thickness, } \\
\mathrm{cm}\end{array}$ & $\begin{array}{c}\text { Cold } \\
\text { moderator } \\
\text { mass, } \mathrm{g}\end{array}$ & $\begin{array}{c}\text { Neutron brightness } \\
\text { below 1meV, } \\
\mathrm{n} / \mathrm{cm}^{2} \cdot \mathrm{s} \cdot \mathrm{meV} \cdot \mathrm{ster}\end{array}$ & $\begin{array}{c}\text { Neutron } \\
\text { heating, W }\end{array}$ & $\begin{array}{c}\text { Photon } \\
\text { heating, W }\end{array}$ \\
\hline para-LH 2 & 3.6 & 215.154 & $\begin{array}{c}3.26 \mathrm{e}+08 \\
( \pm 4.89 \%)\end{array}$ & $\begin{array}{c}0.506 \\
( \pm 0.36 \%)\end{array}$ & $\begin{array}{c}3.397 \\
( \pm 0.26 \%)\end{array}$ \\
\hline ortho-LH 2 & 1.6 & 126.364 & $\begin{array}{c}2.94 \mathrm{e}+08 \\
( \pm 2.43 \%)\end{array}$ & $\begin{array}{c}0.369 \\
( \pm 0.35 \%)\end{array}$ & $\begin{array}{c}3.578 \\
( \pm 0.26 \%)\end{array}$ \\
\hline $\begin{array}{c}\text { solid } \\
\text { methane }\end{array}$ & 1.0 & 552.963 & $\begin{array}{c}3.70 \mathrm{e}+08 \\
( \pm 2.36 \%)\end{array}$ & $\begin{array}{c}0.405 \\
( \pm 0.32 \%)\end{array}$ & $\begin{array}{c}4.520 \\
( \pm 0.26 \%)\end{array}$ \\
\hline
\end{tabular}

Table VIII. Comparison of the cold neutron source parameters for $100 \mathrm{KW}$ electron beam with 100 and $200 \mathrm{MeV}$ electron energy for cold neutron source configuration with single moderator bulb and single neutron channel

\begin{tabular}{|c|c|c|}
\hline Design parameter & $100 \mathrm{MeV}$ electron energy & $200 \mathrm{MeV}$ electron energy \\
\hline $\begin{array}{c}\text { Neutron brightness below } \\
1.0 \mathrm{meV}, \mathrm{n} / \mathrm{cm}^{2} \cdot \mathrm{s} \cdot \mathrm{meV} \cdot \mathrm{ster}\end{array}$ & $\begin{array}{c}3.59 \mathrm{e}+08 \\
( \pm 3.85 \%)\end{array}$ & $\begin{array}{c}3.46 \mathrm{e}+08 \\
( \pm 2.36 \%)\end{array}$ \\
\hline Neutron heating, W & $\begin{array}{c}0.158 \\
( \pm 0.51 \%)\end{array}$ & $\begin{array}{c}0.174 \\
( \pm 0.50 \%)\end{array}$ \\
\hline Photon heating, W & $\begin{array}{c}0.826 \\
( \pm 0.28 \%)\end{array}$ & $\begin{array}{c}0.836 \\
( \pm 0.27 \%)\end{array}$ \\
\hline
\end{tabular}




\section{Summary}

This study examined different cold neutron source configurations for the KIPT neutron source facility. Optimal performance parameters were defined for different cold moderators and geometrical configurations. The design configuration with three cold moderator bulbs and three neutron channels is the preferred option. It provides flexibility for using different cold moderator materials and three cold neutron channels. In addition, it occupies a small volume relative to the other configurations. Graphite column and lead shield are required to enhance the performance of the cold neutron source. 


\section{Reference}

1. Y. Gohar, I. Bolshinsky, D. Naberezhnev, "Accelerator-driven sub-critical facility: Conceptual design development," Nuclear Instrument and Methods in Physics Research A 562 (2006)870-874.

2. Y. Gohar, I. Bolshinsky, J. Bailey, H. Belch, D. Naberezhnev and J. Duo, "Accelerator Driven Sub-Critical Facility: Conceptual Design Development," NIMPR A562, Proc. of AccApp05, 23 June 2006, Pages 870-874.

3. P. Kopetka, R.E. Williams, J.M. Rowe, "NIST Liquid Hydrogen Cold Source," National Institute of Standards and Technology Report, NISTIR-7352

4. Denise B. Pelowitz, editor, "MCNPX ${ }^{\mathrm{TM}}$ USER'S MANUAL," Los Alamos Report, LA-CP-05-0369, April 2005.

5. R. B. Pond, et al., Neutronic performance of the WWR-M research reactor in Ukraine, Proceedings of the $24^{\text {th }}$ International Meeting on Reduced Enrichment for Research and Test Reactors, San Carlos de Bariloche, Argentina, 3-8 November 2002.

6. W. P. Swanson, "Radiological Safety Aspects of the Operation of Electron Linear Accelerators," IAEA, Vienna, 1979, Pages 61 94.

7. J. A. Bucholz, "Physics Analysis in the Design of the HFIR Cold Neutron Source," Proceedings of the XIII International School on Nuclear Physics, Neutron Physics and Nuclear Energy, Varna, Bulgaria, Sept. 27- Oct. 3, 1999. 


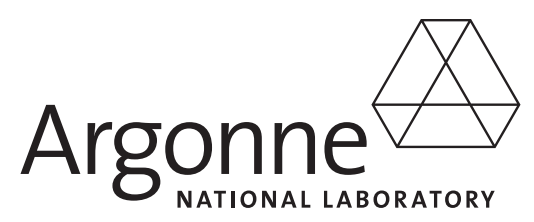

Nuclear Engineering Division

Argonne National Laboratory

9700 South Cass Avenue, Bldg. 208

Argonne, IL 60439-4842

www.anl.gov 